\title{
Conceptual Design Report for the Project to Install Leak Detection in FAST-FT-534/548/549
}

\author{
Kelly J. Galloway \\ Published July 1992 \\ Idaho National Engineering Laboratory \\ EG\&G Idaho, Inc. \\ Idaho Falls, Idaho 83415
}

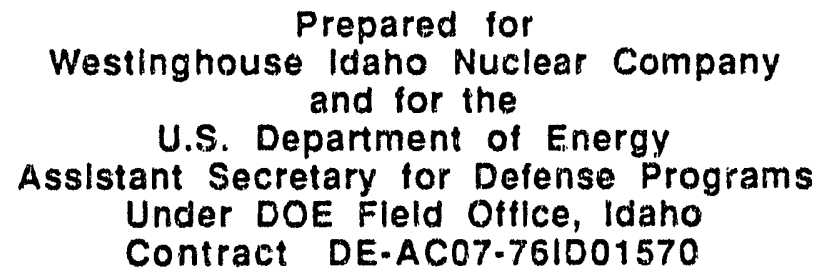




\section{PROJECT SUMMARY}

This report provides conceptual designs and design recommendations for installing secondary containment and leak detection systems for three sumps at the Fluorinel and Storage Facility (FAST), CPP-666. The FAST facility is located at the Idaho Chemical Processing Plant (ICPP) at the Idaho National Engineering Laboratory (INEL).

The three sumps receive various materials from the FAST water treatment process. Sump VES-FT-534 receives mixed hazardous wastes consisting mainly of contaminated basin water with some dilute nitric acid. Sump VES-FT-548, the Non-contaminated Sump, receives the steam condensate and floor drain waste streams; and sump VES-FT-549, the Chemical Waste Sump, primarily receives the materials coming from the chemical makeup tanks, mainly dilute nitric acid and dilute sodium hydroxide. Currently, none of the sumps have secondary coniainment with leak detection capability. In designing the new system, special cunsiderations should be taken for the material selection. The materials used to fabricate the secondary containment/leak detection systems need to be chemically inert and non-reactive with the materials the sumps are designed to contain.

This project involves sump upgrades to meet appropriate environmental requirements. The steps include: providing sump modifications or designs for the installation of leak chases and/or leakage accumulation, coating the sump concrete with a chemical resistant sealant (except for sump VES-FT-534 which is already lined with stainless stee?) to act as secondary containment, lining the sumps with a primary containment system, and providing a means to detect and remove primary containment leakage that may occur.

The recommended design for secondary containment involves the use of a synthetic reinforced coating system. Sentry Polymers, Inc. of Freeport, Texas, provides secondary containment systems with leak detection capability specifically designed to meet environmental requirements for hazardous material containments, Semstone materials. A reinforced coating system is applied to pre-installed false walls and floor, and the false walls and floor 
provide the necessary primary containment. The present sump will be the secondary containment which will collect any leakage. The Semstone lining materials are currently being tested to determine suitability for this project's application. Alternative lining materials are being investigated.

A leak detection pipe from the top of the sump provides access to where leaked materials would collect on the current sump floor. A leak detection device with alarm and a pump will be installed in this pipe. The alarms would actuate when liquid leakage from the primary containment has is detected. Local control panel (LCP) LCP-22 and LCP-21 are located in the FAST water treatment area and are easily accessible. Alarm panel LCP-22 will be used for sump VES-FT-534 leak detection alarm, and alarm panel LCP.21 will be used for sumps VES-FT-548 and VES-FT-549.

In the event of a sump liner leak, the leak detection system would alarm. Operations personnel would then assess the leakage and manually activate the pump as necessary. The pump will simply return the leaked contents back into the primary containment. This process will continue until the leakage has been determined excessive and/or a point in the plant process is reached where the sump system can be shut down, the sump contents removed, and the liner repaired. This system will prevent any inadvertent release of sump contents to the environment.

The secondary containment/leak detection systems will be designed for simplicity of maintenance, serviceability of the leak detection system and secondary containment pump, and testing capability of the system for proper operation. The system will meet FAST facility management and production personnel requests and will meet the requirements of the Resource and Recovery Act (RCRA) 40 Code of Federal Regulations (CFR) 265.193 for double containment and Department of Energy (DOE) Order 6430.1A for design criteria. 


\section{CONTENTS}

PROJECT SUMMARY

Page

1. PROJECT DESCRIPTION

1.1 Stainless Steel Liner Feasibility ............... 2

1.2 Secondary Containment Alternative .............. 3

2. INITIAL PREPARATION ................... 6

2.1 Preliminary Safety Analysis ..............66

2.2 Training ............. . . . 6

2.3 General Sump Decontamination Procedures . . . . . . . . 7

2.4 Sump Data . . . . . . . . . . . . . . . . 8

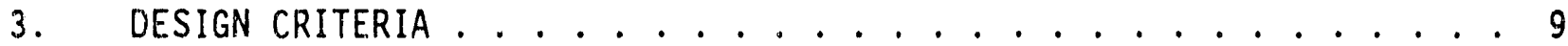

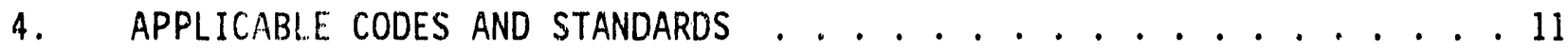

4.1 General Reference Codes ................. . 11

4.2 Department of Energy Codes .............. . 11

4.3 Idaho National Engineering Laboratory Documents ........ II

4.4 Idaho Chemical Processing Plant Documents .......... . 11

5. CONSTRUCTION SPECIFICATIONS OUTLINE . . . . . . . . . . . 13

5.1 General Specifications ................... 13

5.2 Civil/Structural Specifications . . . . . . . . . . . . 13

5.3 Mechanical Specifications................ 13

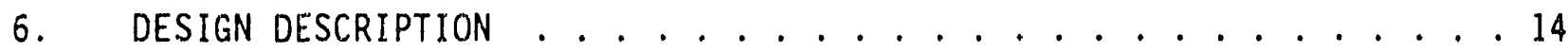

6.1 Sump Concrete Leak Chase Design .... . . . . . . . . . 14

6.1 .1 Sumps VES-FT-548 and VES-FT-549.......... 14

6.1 .2 Sump VES-FT-534 ................ . . . . . . . . .

6.2 Paint Sealant . . . . . . . . . . . 15

6.3 Sump Liner Design . . . . . . . . . . . . . . . . . 15

6.3.1 Sump VES-FT-548 Design . . . . . . . . . . . . . . . 17

6.3 .2 Sump VES-FT-549 Design . . . . . . . . . . . . . . 17

6.3.3 Sump VES-FT-534 Design . . . . . . . . . . . . . . 19

6.4 Pump and Piping ................. . 21

6.4 .1 Pump Selection ................. . . 21

6.4.2 Air Supply Piping . . . . . . . . . . . . . . 22

6.4 .3 Flexible Discharge Line............. . 22

6.5 Electrical and Instrumentation ............. . 23

7. OPERATIONS TESTING AND QUALITY CONTROL .............. 24

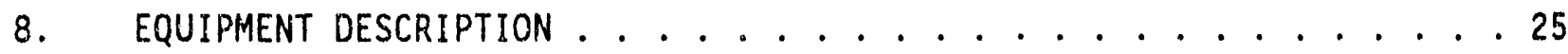

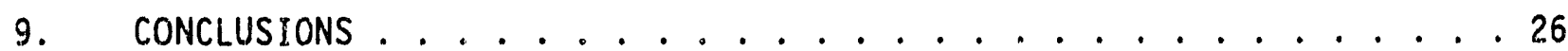




\section{APPENDICES}

APPENDIX A. Resource and Recovery Act (RCRA) 40 Code of Federal Regulations (CFR) 265.193, Containment and Detection of Releases.

APPENDIX B. WINCO Safety Approval for Secondary Contiinment System.

APPENDIX C. Vendor Information: Air Operated Pumps, Leak Detection Devices, Liner Secondary Containment, Paint Coaters.

APPENDIX D. Sentry Polymers, Inc. Secondary Containment/Leak Detection Specifications.

APPENDIX E. Calculations for Material Costs.

FIGURES

Figure 1. Sump VES-FT-548 and Sump VES-FT-549 . . . . . . . . . . . 18

Figure 2. Sump VES-FT-534 ................. 20

TABLES

Table 1. Sump Dimensions for Design .................8

Table 2. Design Components and Cost Estimations ........... 25

\section{ACRONYMS}

CFR

CPP-666

DOE

FAST

FRP

ICPP

INEL

IH

LCP

OHP

RCRA

SOP

VES-FT-548

VES-FT- 549

VES-FT-534

WINCO

Code of Federal Regulations

Fluorinel and Storage Facility

Department of Energy

Fluorinel and Storage Facility

Fiberglass Reinforced Plastic

Idaho Chemical Processing Plant

Idaho National Engineering Laboratory

Industrial Hygiene

Local Control Panel

Operations Health Physics

Resource and Recovery Act

Standard Operating Procedures

Non Contaminated Sump in the Fluorinel and Storage Facility

Chemical Waste Sump in the Fluorinel and Storage Facility

Contaminated Waste Sump in the Fluorinel and Storage Facility

Westinghouse Idaho Nuclear Company 


\section{PROJECT DESCRIPTION}

This project design involves upgrade modifications for three sumps located in the water treatment area of the FAST facility (CPP-666), sumps VES-FT-534, 548, and 549. All three sumps are currently in service and are part of the water treatment process. As indicated in RCRA 40 CFR 265.193, secondary containment criteria, and DOE Order 6430.1A, general design criteria, sumps receiving hazardous materials are to be provided with secondary containment and a means to detect leakage of the primary containment. (See Appendix $A$ for the applicable RCRA 40 CFR 265.193 regulations.) A11 three sumps may potentially receive hazardous materials. Diluted nitric acid and/or sodium hydroxide are the constituents of primary concern. Sump VES-FT-534 may also receive some radioactive materials. Presently, none of the sumps have secondary containment or leak detection capability.

A11 three sumps will be cleaned and decontaminated by WINCO Production personnel prior to starting the secondary containment/leak detection project. Modifications for leak chases and optimal leakage collection will be made to the sump concrete foundation for the two sumps not already lined with stainless steel. The sump concrete surface will then be sealed with a chemical resistant coating. A secondary containment/leak detection system will be installed by fabricating a containment liner in each sump. The liner is to provide primary containment of hazardous materials and a space between the liner and the current sump wall. Any liner leakage will flow to the secondary containment leak collection area. A leak detection device with alarm capability and a pump will be installed on the current sump floor between the liner and the existing sump floor. This system will be able to detect and remove any leakage from the primary containment.

The stainless steel liner primary containment system feasibility was evaluated. Section 1.1 identifies some potential problems and disadvantages of installing a stainless steel liner in the sumps. Sectior, 1.2 provides an alternative to the stainless steel liner and lists the advantages and potential problems associated with this system application and design. The conceptual design and design recommendations are developed from the alternative provided. 


\subsection{Stainless Steel Liner Feasibility}

Constructing a stainless steel liner in the concrete sumps would be labor intensive in fabrication and quality assurarice and expensive to install. The following list identifies some potential problems and disadvantages of installing a stainless steel liner.

(1) The process of installing the stainless steel liner may create additional problems. There are no embeds in the concrete to anchor or fabricate the stainiess steel liner to; therefore, a liner support or bracing system will need to be designed and installed. The most feasible option investigated would be to insta 17 "embeds" by fastening flat bar and angles to the concrete using Hilti anchors and then weld the liner sheets to the "embeds". This would be an arduous task and could require up to 300 holes in the sump concrete walls.

(2) The liner cannot be prefabricated and inserted due to the various inlet and discharge lines, pumps, and instrumentation. A major portion of the stainless steel liner would need to be fabricated in situ. One wall for sump VES-FT-549, (10 ft $6 \mathrm{in}$. by $6 \mathrm{ft}$ by $3 / 16$ in., 304 L stainless steel), would weigh approximately 500 pounds. The stainless steel sheet, therefore, would need to be cut in fairly small sections for handling and working around the various obstacles. This would require a large quantity of welds and embeds. (It would take approximately 300 feet of weld to fabricate a stainless steel liner for VES-FT-549. This does not. include the seal welds for the Hilti anchors or embed emplacements.)

(3) Quality assurance on the stainless steel liner would also be extensive. It may be required to liquid penetrant test $100 \%$ of the welds according to WINCO standard Operating Instructions (SOI) 8.9.1. and AWS D1.1. This would require a great deal of time and effort. Both the stainiess steel liner construction and inspection could cause a significant down time of the sump operations. 
(4) The stainless steel liners should be fabricated up to the inlet weirs running into the sump. A gap exists between the primary containment and the existing sump concrete (secondary containment). The gap is necessary to allow any sump wall leakage to flow to the floor of the secondary containment, and is therefore unavoidable. It would be difficult to seal the top of the stainless steel liner to the concrete sump wall to prevent any materials from entering the secondary containment area from the weirs or overflow from the liner. It would be difficult to verify whether the materials detected in the secondary containment resulted from a leakage problem or ran in from the weirs.

(5) Welding and operating in confined space areas will require significant safety measures for proper ventilation and worker safety.

\subsection{Secondary Containment Alternative}

Sentry Polymers, Inc. constructs environmental secondary containment systems that can be fabricated in situ with leak detection capability. Currently their lining system materials are being evaluated for performance. Alternative lining materials are being investigated. The advantages of this type of system are as follows:

(1) This product would be more effective than the stainless steel liner and is intended specifically for the project applications. The entire sump could be lined if desired, including working around the weirs and the pipes that protrude into the sumps. It would also be able to seal the top of the liner to the concrete. This would prevent weir materials from flowing into the secondary containment area or having the sump liner overflow into the secondary containment.

(2) The system provides for a leakage accumulation space under the sump liner. The existing sump floor concrete may require some modifications to provide optimal leak collection. The system also provides for a "leak detection pipe". The pipe runs down through 
the sump liner and enters into the accumulation space on the floor of the secondary containment. The pipe is sealed to prevent primary containment contents from leaking directly into the leakage accumulation area (secondary containment). A leak detection device as well as a small pump can be placed inside the pipe oll the sump floor.

(3) The system would be easier to install compared to the stainless steel liner system. It would be a bit more extensive than applying a paint sealant, but would require less labor than for the stainless steel liner. This also means less down time of the sump operations. The lining system can be constructed around the various pumps, piping, and instrumentation currently in the sumps. Also, because the materials are relatively light weight, most of the liner fabrication may be done outside of the sump.

(4) This particular system will meet RCRA environmental requirements for hazardous material handling systems.

(5) 13 Molar (62\%) nitric acid and/or 19 Molar (50\%) sodium hydroxide are used in the water treatment process. Although very unlikely, ful1 strength (62\%) nitric acid or (50\%) sodium hydroxide could potentially enter the sumps under a worst case scenario. Sentry Polymers, Inc. recommends Semstone ${ }^{\circledR} 870$ for this application. This Sentry material contains a potential carcinogen, styrene. The ICPP $N$ \& IS Department generally does not allow potential carcinogens to be used unless justification is providec :id/or a suitable alternative can not be located. The secondary containment lining material provided by Sentry polymers, Inc. (Semstone ${ }^{\circledR}$ 870), has met WINCO Industrial Hygiene and Safety Department approval (See Appendix B). The WINCO Maintenance Plant Services provided a list of recommended paint coating companies to contact for an alternative coating material. The coatings investigated capable of handling the $62 \%$ nitric acid, however, contained styrene. 
(6) The sumps are confined space areas. Proper ventilation and safety engineering will be required in order to assure worker safety. 


\section{INITIAL PREPARATION}

\subsection{Preliminary Safety Analys is}

In the design, construction, and operation phases of the sump liner/leak detection systems, good health and safety principles should be applied with safety concerns properly identified and addressed.

A11 three sumps have been in service since early 1980s. No maintenance records were available; therefore, it is assumed that no maintenance of the sumps have been performed since construction. Surveys of the sump walls and floor and residual materials will be necessary to determine each sump's radiological and chemical hazards. These surveys will also give a better indication of the necessary steps for sump maintenance and upgrades. It will be necessary to enter the sump to make field verification measurements, since the drawings showing its configuration aren't clear.

Given a safe design, adequate procedures, proper training, and irudustrial hygiene enforcement, the risks to personnel and environment are believed to be low and acceptable. The principal risks will be encountered during the sump decontamination/cleaning process and during installation of the sump liners.

\subsection{Training}

All personnel required to enter the sumps to work may be required to have the following general training:

- Confined Space Entry Training

- Confined Space Rescue Training (Health Physics personnel)

- Radiation Worker Training

- Chemical Training

- Respirator Training

- Heat Stress Training

Al1 three sumps are confined space zones; therefore, confined space entry training will be required when working in the sumps. The definition for confined space is provided. Special non-standard health physics procedures 
may be necessary during secondary containment installation.

Confined space (29 CFR 1910) - "An enclosure such as a storage tank, process vessel, boiler, silo, tank car, pipeline, tube, duct, sewer, underground utility vault, tunnel, or pit having limited means of egress and poor ratural ventilation and which may contain hazardous contaminants or be oxygen deficient."

Sump VES-FT-534 is known to be radiologically contaminated and is considered a Zone III area. Sumps VES-FT-548/549 systems were not initially designed to receive radioactive materials, and are not suspected to be contaminated. Although only sump VES-FT-534 is known to be contaminated at this time, radiation worker training may be required for personnel working on all the sumps. Additional training may include site-specific training to familiarize personnel to the risks or hazards involved with the area and/or their specific task assignments.

\subsection{General Sump Decontamination Procedures}

Sump VES-FT-534 is a Zone III radiological area; however, it is believed that the sump can be "cleaned" considering the contamination type and level. WINCO Production personnel will perform the decontamination efforts. In decontaminating the sump, appropriate WINCO procedures should be followed. The general procedure is outlined below:

1. Radiation Work Permit obtained.

2. The sumps surveyed for the contamination $n$ re ard extent by WINCO Operations Health Physics (OHP) Peison:el.

3. The sump concrete cecontaminated per WINCO decontamiration procedures.

4. The sumps resurveyed for contamination by WINCO OHP PersonneT.

5. Steps 3 and 4 will be repeated until the sump is decontaminated to a point where decontamination efforts are no longer effective. WINCO Operations Health Physics personnel are responsible for determining the requirements for radiation monitoring and the parameters defining the level of decontamination necessary. 


\subsection{Sump Data}

Tabie 1. provides sump dimensions, capacity, and surface area information useful for the secondary containment/leak detection system design. For sumps VES-FT-548 and VES-FT-549, the liners should extend at the least up to the lowest overflow keir. The dimensions provided in Table 1 for sumps VES-FT-548 and VES-FT-549 are field measurement values.

Table I. Sump Dimensions for Design

\begin{tabular}{|l|l|l|l|l|l|l|}
\hline Sump & width & Length & Depth & $\begin{array}{l}\text { Minimum } \\
\text { Height of } \\
\text { iner from } \\
\text { sump floor }\end{array}$ & $\begin{array}{l}\text { Volume } \\
\text { capacity } \\
\text { of jiner } \\
\left(\mathrm{ft}^{3}\right)\end{array}$ & $\begin{array}{l}\text { Total } \\
\text { Concrete } \\
\text { Surface area } \\
\text { covered } \\
\left(\mathrm{ft}^{2}\right)\end{array}$ \\
\hline VES-FT-534 & $4^{\prime}$ & $8^{\prime}$ & $25^{\prime}$ & $5^{\prime} 6^{\prime \prime}$ & 176 & 164 \\
\hline VES-FT-548 & $5^{\prime} 6^{\prime \prime}$ & $5^{\prime} 6^{\prime \prime}$ & $8^{\prime} 4^{\prime \prime}$ & $5^{\prime} 4^{\prime \prime}$ & 161 & 148 \\
\hline VES-FT-549 & $6^{\prime}$ & $6^{\prime}$ & $13^{\prime} 8^{\prime \prime}$ & $10^{\prime} 7^{\prime \prime}$ & 381 & 290 \\
\hline
\end{tabular}

a. These values are measurements taken. Orawinge indicate that the sump VES-FT-548 is $8 \mathrm{ft} 6$ in. deep and sump VES-FT-549 is $13 \mathrm{ft} 9 \mathrm{in}$, deep.

For all three sumps, a conservative estimate for the sump contents temperature is between $40^{\circ} \mathrm{F}$ to $100^{\circ} \mathrm{F}$. The water, in all three cases, is generally ambient temperature as it entering the sumps. Water will always be present in the sumps. This remaining water will dilute any nitric acid and/or sodium hydroxide that drains into the sump. 


\section{DESIGN CRITERIA}

RCRA 40 C.FR 265.193 provides the driving criteria prompting action for this project. It provides the environmental design requirements for containment systems handling hazardous constituents. Sumps VES-FT-534 and VES-FT-549 potentialiy receive hazarcious and corrosive liquids and, therefore, must comply with the regulations in order to meet the current environmental requirenents for continued operation. Sump VES-FT-548 currently does not receive hazardous materials. For management practices and potential future IIses, however, sump VES-FT-548 will have the same design requirements as for VES-FT-534 and VES-FT-549 (hazardous material containment systems).

The design criteria is outlined in the Functional and Operational Requirements to Install Leak Detection in FAST-FT-534/548/549 (GPP..NMP-93-10), May 1992, by $T$. H. Waite. The secondary containment/leak detection systems shall have a 40 year design life and will be designed for simplicity of operation, maintenance, anci servicing. The system operation will be safe and reliable and will be designed so that periodic tests can be performed to ensure proper operation.

The materials and equipment selected in the secondary containment system design must be capable of potentially handling 13 Molar (62\% concentration) nitric acid and/or 19 Molar ( $53 \%$ concentration) sodium hydroxide under worst case scenarios. However, the probability of those materials entering the sumps at maximum concentration is very smal1. The primary containment liner will be fabricated in such a way that it allows leaked materials to collect in the secondary containment (existing sump floor) between the liner and concrete foundation. The leak detection system will be capable of detecting and pumping out the leakage. Alarms shall actuate in the event of a primary containment liner leak. The pump will then be manually activated by the FAST personnel. The leakage will be pumped back into the primary containment until a point in the water treatment process is reached where operations can be stopped and the liner repaired. The system installation will not alter the existing sump operations, and modifications to the sump inlet and discharge lines will occur only if absolutely necessary. 
The piping, equipment, and installation shall meet the requirements of a "Low Hazard Facility" as outlined in the UCRL-15910, "Design and Evaluation Guidelines for Department of Energy Facilities Subjected to Natura? Phenomena," June 1990 and shall meet the requirements for the appropriate codes and standards.

This project has been designated Quality Level II by WINCO Quality Methods and Procedures (QMP) 3-3 and WINCO Standard Operating Procedures (WSOP) WE-1. The Quality Program Plan (QPP) invokes the applicable requirements of the DOE-ID Orders 5700.6C and 4700.1, ANSI/ASME NQA-1, and the WINCO Quality Manual. 


\section{APPLICABLE CODES AND STANDARDS}

Designs, material selection, examination, testing, inspection, certification, and documentation of this project shall comply to the applicable portions of the specifications, codes, and standards listed below.

\subsection{General Reference Codes}

- American Society of Testing Materials (ASTM) Standards.

- American Society of Mechanical Engineers (ASME/ANSI) B31.3, "Chemical Plant and Petroleum Refinery Piping."

- American Society of Mechanical Engineers (ASME) ASME/ANSI NQA-1, "Quality Assurance Program Requirements for Nuclear Facilities."

- Uniform Building Code (UBC).

- Uniform Plumbing Code (UPC).

- 29 Code of Federal Regulations 1910, "Occuprational Safety and Health Administration (OSHA) Standards."

\subsection{Department of Energy Codes}

- DOE-ID Order 6430.1A, "U. S. Department of Energy General Design Criteria Manual."

- DOE-ID 0550, "Standard Operation Safety Requirements."

- DOE-ID 5700.6C, "Quality Assurance."

- DOE-ID 4700.1, "Project Management System."

- UCRL-15910, "Design and Evaluation Guidelines for Department of Energy Facilities Subjected to Natural Phenomena."

\section{3 !ảaho National Engineering Laboratory Documents}

- INEL Architectural-Engineering Standards.

\subsection{Idaho Chemical Processing Plant Documents}

- WINCO SOP WE-1, "Quality Level Designation."

- WINCO SOP WE-2, "Construction Safe Work Permit."

- WINCO SOP WE-31, "Natural Phenomena Classification." 
- WINCO SOP WP-3, "Facility Outages and Excavation Permits."

- WINCO SOP WS 1 , "Classification, Review, an Approval of Documents."

- WINCO SOP WP-10, "Isolation and Tag/Lockout of ICPP Systems and Equipment."

- WINCO Quality Assurance Manual

- WINCO Industrial Safety Manual. 


\title{
5. GUIDE SPECIFICATIONS OUTLINE
}

Design, construction, maintenance, and equipment selection for construction projects will be in accordance with specifications.

\subsection{General Specifications}

\author{
SECTION TITLE \\ 01005 Summary of Work \\ 5.2 Civil/S ructural Specifications \\ SECTION TITLE \\ 03600 Concrete Cutting \\ $09810 \quad$ Chemical Resistant Coating \\ Lining Concrete Pits for the Purpose of Leak Detection \\ 5.3 Mechanical Specifications

$\begin{array}{ll}\text { SECTION } & \text { IITLE } \\ 15404 & \text { Air Supply Piping } \\ 15160 & \text { Pumps } \\ 15980 & \text { Instrumentation } \\ 16141 & \text { Wiring Devices }\end{array}$




\section{DESIGN DESCRIPTION}

RCRA 40 CFR 265.193 provides the environmental design requirements for containment systems handling hazardous materials. Sumps VES-FT-534, -548, and -549 receive hazardous materials and must comply with requirements for continued operation. The following sections provide design recommendations for sump modifications, secondary containment, and leak detection systems that will rectify the potential RCRA deficiencies and bring the sumps into environmental compliance - keeping in mind safety and simplicity of operation and maintenance. (See Appendix A for the relevant RiRA 40 CFR 265.193 regulations.)

\subsection{Sump Concrete Leak Chase Design}

\section{1 .1 Sumps VES-FT-548 and VES-FT-549}

RCRA 40 CFR 265.193 (c)(4) states that "secondary containment systems must be sloped or otherwise designed to drain and remove liquids resulting from leaks, spills, or precipitation from the primary containment." Presently, it is not known if the sump floors for VES-FT-548 or VES-FT-549 are sloped or if inherent low spots exist in construction. The sumps are currentiy in service, making sump floor observations difficult, and the available drawings do not provide sump floor design detail. It has been assumed that these sump floors are basically flat concrete surfaces. If later proved otherwise, the sump leak channels and location of the leakage accumulation area can be modified for optimal leakage removal.

A leak chase system or leak accumulation system needs to be designed to assure proper leakage removal from the secondary containment area. The options are to modify the existing sump floor or to design, fabricate, and install a system to collect any leakage.

The simplest option would be to modify the existing sump floor. This would entail coring a 16 inch diameter by 1 inch to 4 inch deep section in the sump floor. This cored section will be referred to as the leakage accumulation area. The leakage accumulation area will provide a low point in the sump floors for leaked material to collect. Grooves extending radially from the 
leakage accumulation area would be cut into the concrete floor. These channels would be approximately $\frac{1}{2}$ inch wide and $\frac{1}{2}$ inch deep. The grooves would direct leaked materials from the sump extremities to the accumulation area.

\subsubsection{Sump VES-FT-534}

The bottom $5 \mathrm{ft} 6 \mathrm{in}$. of sump licS-FT-534 is 1 ined with stainless steel. Channeling the sump floor for leakage accumulation, therefore, will not be possible. According to the available drawings, however, there is reason to believe that the sump floor is sloped. If sloped, the sump already has the necessary leakage accumulation capability.

\subsection{Paint Sealant}

A paint sealant will provide the secondary containment for the sumps not already lined with stainless steel and serve as an added safety and maintenance feature contributing to the sump integrity and reliability. Of the three sumps investigated, sump VES-FT-549, the Chemical Waste Sump receives the larger amount of hazardous materials, with nitric acid and sodium hydroxide being of primary concern. Thirteen (13) Molar (62\%) nitric acid and/or nineteen (19) Molar (50\%) sodium hydroxide are used in the water treatment process.

Before the hazardous material enters the sumps, the nitric acid and/or sodium hydroxide is diluted considerably with water. The probability of having straight 13 Molar nitric acid or 19 Molar sodium hydroxide enter the sump liners and then leak out into the secondary containment area is very slight; however, paint sealant selection assumes this worst case scenario for design and provides the required secondary containment. (See Appendix $C$ for paint vendor information.)

\subsection{Sump Liner Design}

As discussed, Sentry Polymers, Inc. provide secondary containinent liner systems. These systems are constructed of Semstone ${ }^{\circledR}$ coater products and are applicable to this project application. The Semstone liner materials are 
currently being evaluated to determine their chemical resistivity and reliability. Alternative materials are being investigated. The Semstone ${ }^{\circledR}$ secondary containment design provides a false floor and false wall liner to provide primary containment and secondary containment with leakage detection and removal. (See Appendix $D$ for secondary containment specifications.) The described conceptual design assumes Semstone ${ }^{\circledR} 870$ is used.

The false floor is accomplished by first installing a $1-\frac{1}{2}$ in. thick $\times 1-\frac{1}{2}$ in. square mesh fiberglass grating on the sump floor. The grating is covered with a $1 / 2$ in. fiberglass reinforced plastic (FRP) sheet that is factory molded to one side. The grating and the FRP sheet are then secured in place using concrete anchors with washers installed on 36 inch centers. Once secured, the installed FRP sheet will then be lined with polymer lining material, reinforced with 1.5 oz per square foot chopped strand fiberglass mat to a finished thickness of 125 mils. Grooves or bosses on the bottom of the grating allow liquid materials to travel across the secondary containment floor and prevent pooling.

The false walls are accomplished by fastening $1 / \mathrm{in}$. thick fiberglass sheet to the walls using concrete anchors. Like in the floor installation, the concrete anchors are to be installed at each corner and one in the center of each panel. The installed fiberglass sheet will then be lined with Semstone ${ }^{\circledR}$ 870, reinforced with 1.5 oz per square foot chopped strand fiberglass mat to a finished thickness of 125 mils. The Semstone ${ }^{\circledR} 870$ is not boncled directly to the sump concrete walls. Because of this, a separation between the secondary containment (sump concrete) and primary containment (1 iner) is provided allowing leaked materials to flow between the liner and the secondary containment (sump concrete) walls.

A leak detection/removal pipe (FRP) would be installed to p'ovide access to the leakage accumulation area on the secondary containment floor. The pipe will be approximately $1 \mathrm{ft}$. in diameter allowing adequate space for a small pump and a leak detection device to be placed. The pipe will extend above the liner probably to the top of the sumps in the case of sumps VES-FT-548 and VES-FT-549. 


\subsubsection{Sump VES-FT-548 Liner Design}

Sump VES-FT-548's dimensions are $5 \mathrm{ft} 6$ in. length $\times 5 \mathrm{ft} 6$ in. width $\times 8 \mathrm{ft} 4$ in. depth. A rectangular overflow weir enters the sump on the east side. The base of this weir is $36 \mathrm{in.} \mathrm{from} \mathrm{the} \mathrm{top} \mathrm{of} \mathrm{the} \mathrm{sump.} \mathrm{The} \mathrm{liner,} \mathrm{therefore,}$ would not need to extend more than six inches above the weir. The liner depth will then be approximately $5 \mathrm{ft} 10 \mathrm{in}$. measured from the sump floor. The liner will not interfere with the overflow weir operations and will be sealed to the concrete surface around the top and in the weir area. The liner will cover approximately $160 \mathrm{ft}^{2}$ concrete surface area. The volumetric capacity of the sump up to the overflow weir is $176 \mathrm{ft}^{3}$. The 1 iner will be capable of handling this volume of liquid.

A six inch pipe line enters the sump on the west side and exits the east side. This line does not discharge into the sump and simply passes through. The center of this pipe is approximately $39 \mathrm{in}$. from the top of the sump and will be an obstacle for liner fabrication. A pump and some various instrumentation are mounted on the metal sump cover and extend down into the sump. These items are not to be moved. The pump and instrumentation will be obstacles in liner fabrication. Figure 1 provides a sketch of sump VES-FT-548. The specifications for liner installation are outlined in Appendix $D$.

\subsubsection{Sunip VES-FT-549 Liner Design}

Sump VES-FT-549 dimensions are $6 \mathrm{ft}$ length $X 6 \mathrm{ft}$ width $X 13 \mathrm{ft} 8 \mathrm{in}$. depth. overflow weirs enter the sump on the south side. The base of the lowest weir is approximately $37 \mathrm{in}$. from the top of the sump. The liner, therefore, will only extend approximately six inches above this weir. The liner depth will then be approximately $11 \mathrm{ft}$ measured from the sump floor. The liner will cover approximately $300 \mathrm{ft}^{2}$ of sump concrete surface area.

Again, the liner will be sealed to the concrete surface around the top and in the weir area. As with sump VES-FT-548, a pump and instrumentation are mounted on the metal sump cover. These items extend down into the sump and are not to be altered if at all possible. Sump VES-FT-549 configuration is provided in Figure 1. See Appendix $D$ for specifications. 
Top View

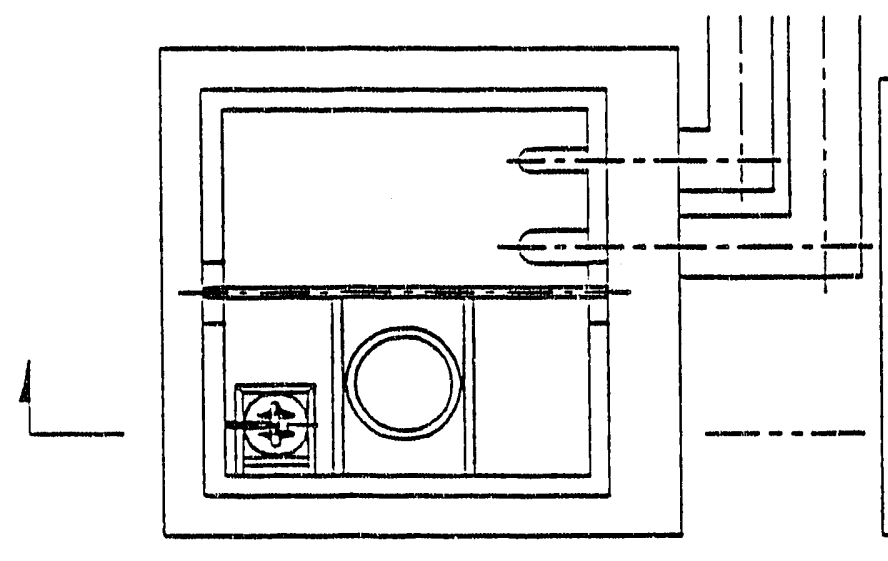

VES-FT-549

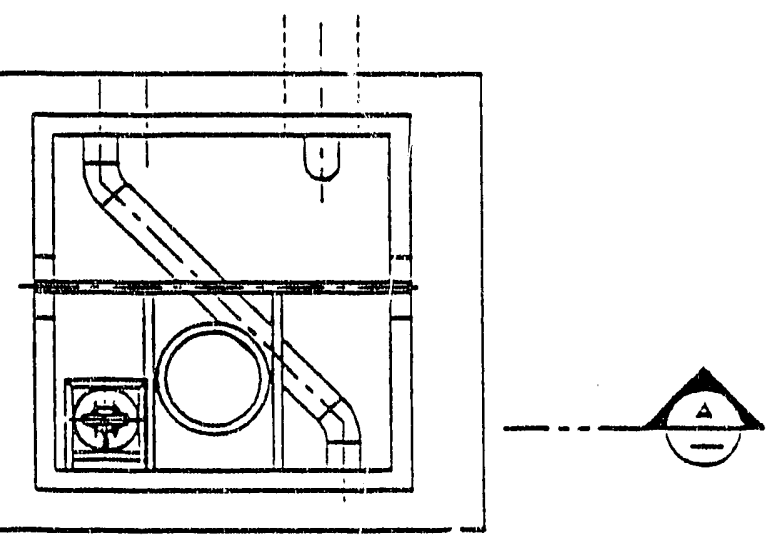

VES-FT-548

Side View

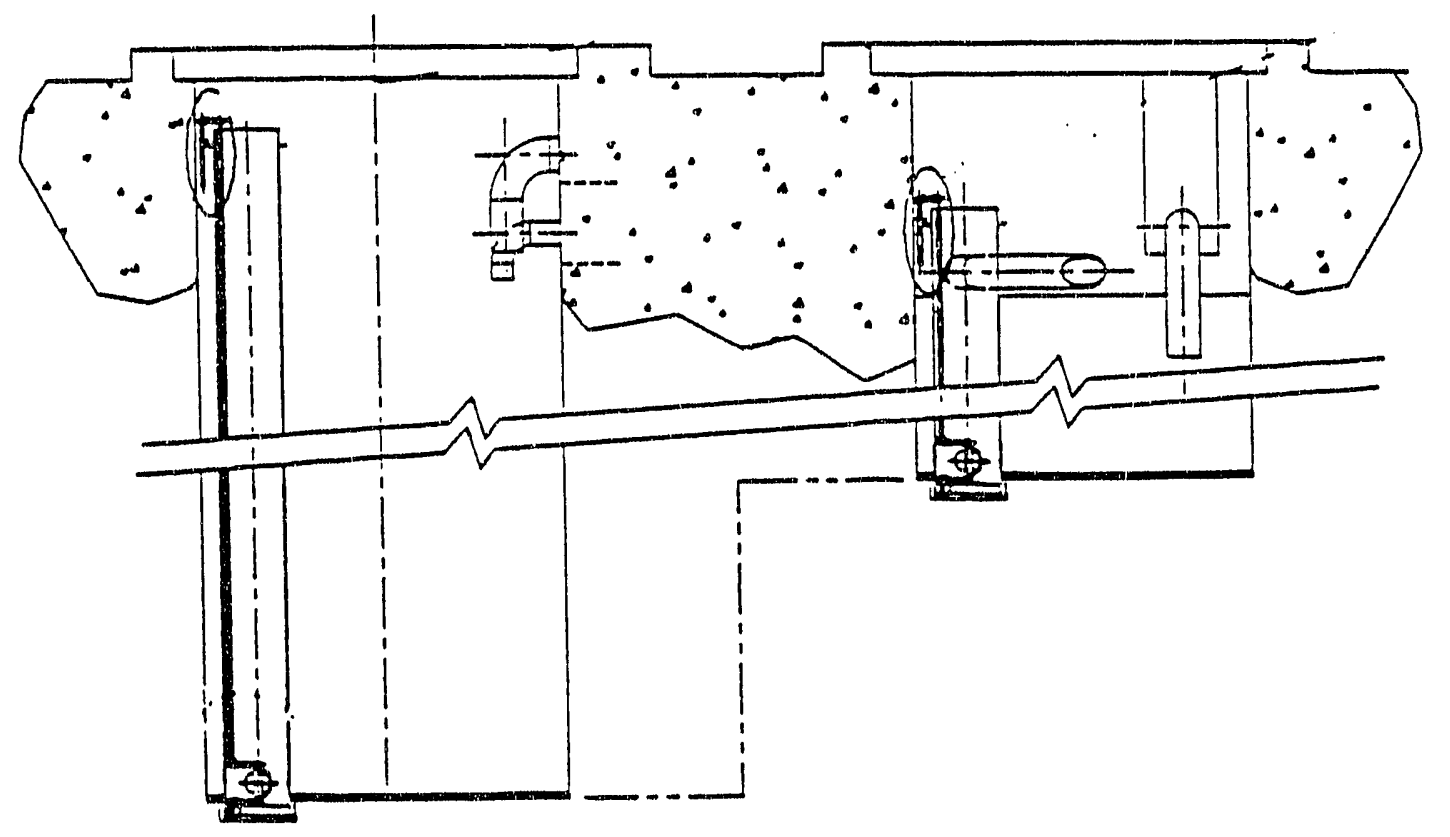

SECTION $\triangle$

Figure 1. Sump VES-FT-548 and Sump VES-FT-549.

(With Secondary Containment/Leak Detection System) 


\subsubsection{SUmp VES-FT-534 Liner Design}

Not much detail is available on sump VES-FT-534. The available drawings are difficult to read and brought up sump configuration questions. It will be necessary to enter the sump to make field verification measurements and observations for subsequent designs. This sump is a zone III area and is covered with a concrete hatch. It is not known what instrumentation, pumps, lines, etc. exist. The drawings indicate that the bottom $5 \frac{1}{2} \mathrm{ft}$ of the sump is lined with a stainless steel liner. Also, a rectangular channel ( $3 \mathrm{ft} \times 3 \mathrm{ft}$ $X 4 \mathrm{ft}$ ) at the base of sump VES-FT-534 possibly connects sump VES-FT-534 to an adjacent sump.

The overal1 dimensions of the sump are $4 \mathrm{ft}$ lengih $\times 8 \mathrm{ft}$ width $X 26 \mathrm{ft}$ depth. As mentioned, the bottom $5 \frac{1}{2} \mathrm{ft}$ of the sump is already lined with stainless steel. For the purpose of this project and unless additional information is obtained, the new liner system will simply cover the existing stainless steel liner. As indicated, it will be necessary to enter the sump to make field verification observations and measurements for secondary containment design and construction. If later additional detail is found, the secondary containment design can be modified.

Even though the sump is already lined, it does not have a secondary containment leak detection or removal system. This feature is required by environmental regulations, since this sump contains hazardous and radioactive materials. The Semstone ${ }^{\circledR}$ secondary containment system can be installed on stainless steel. Figure 2 represents sump VES-FT-534 as indicated in the available drawings. 


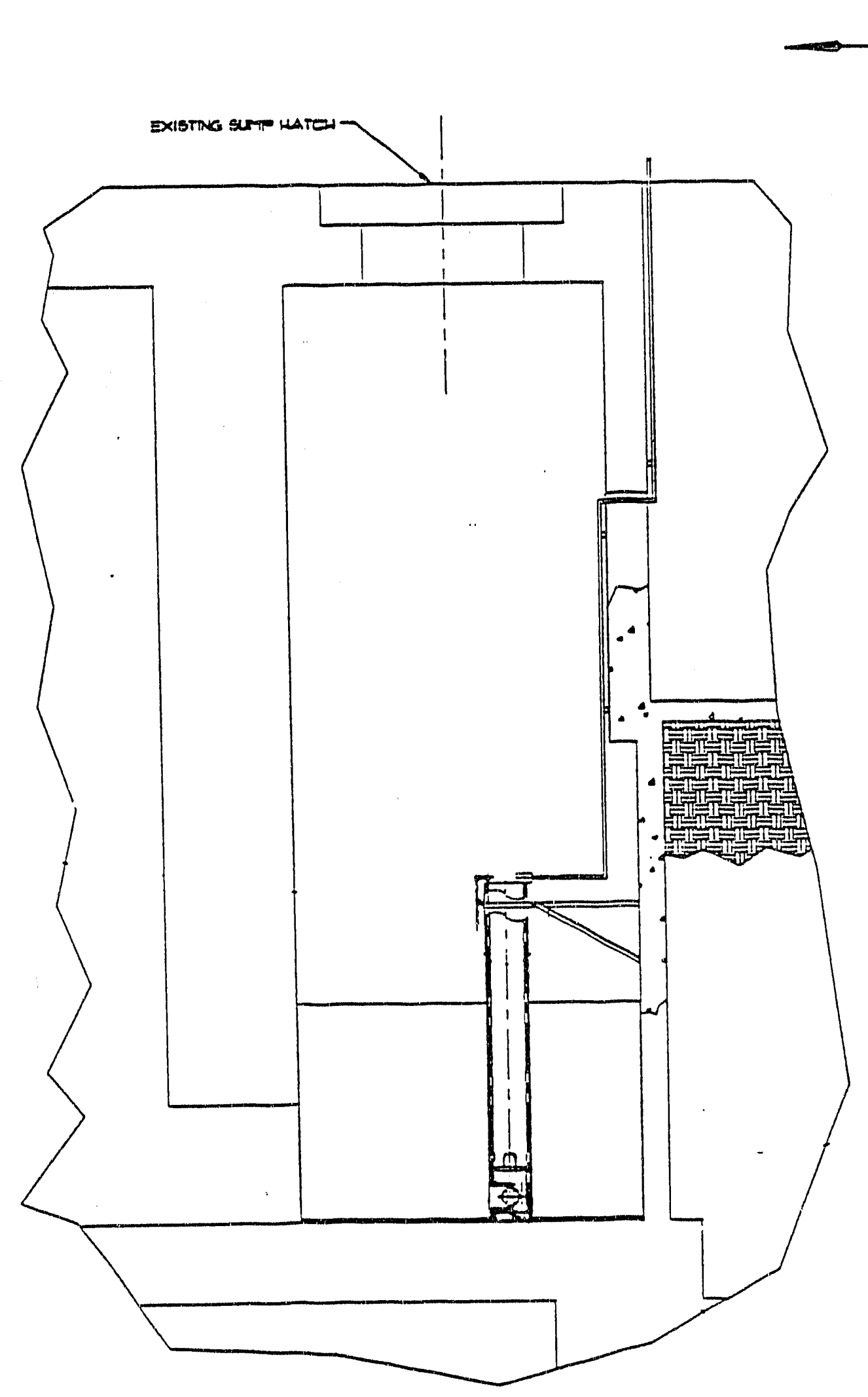

Figure 2. Sump VES-FT-534. 


\subsection{Pump and Piping}

\subsubsection{Pump Selection}

In selecting an appropriate leak removal system, 40 CFR 265.193 (c)(4) was referenced. The pump must efficiently remove leakage from the primary containment. Two options were considered, electrical and air drive pump systems. The FAST facility has 100 psi air capability, and an air driven pump is the preferred option. Requirements for pump system are as follows:

1. Constructed of materials chemically inert and unreactive with sump contents, namely nitric acid, sodium hydroxide, and potential radioactive materials,

2. Capable of pumping at the selected total dynamic head (ft) for each sump,

3. Manually activated,

4. Efficient at removing primary containment leakage,

5. Explosion Proof,

6. Submersible,

7. Small as possible - minimize space or area required, and

8. Removable for maintenance purposes (no permanent base).

9. Preferably be able to pump with no water

Flow rate wasn't a critical design factor in pump selection. It was requested, however, that the pump have a capacity in the range of 2-10 gallons per minute (gpm).

It is important to note that the sumps are confined space areas. This is another limiting factor in pump selection. The equipment placed into or used in these areas should be explosion proof. If not, they should be properly ventilated to prevent a potential safety hazard. As long as air is available for use, the air operated pump is favored over the electric pump. The major advantages of the air operated pumps are: explosion proof, able to run dry continuously without pump damage, self priming, submersible, and more efficient at removing liquids since they don't require a significant heel of water. Appendix $C$ provides vendor information. 


\subsubsection{Air Supply Piping}

One hundred (100) pounds per square inch, gauge (psig) air is available in the FAST facility for pump operations. The recommended pumps for all three sump applications are air operated pumps with a $\frac{1}{4}$. air female NPT inlet. The air supply will be hard piped to the sump areas, valved, and then a $\frac{1}{4}$ in. plastic line will be connected to the pumps. The maximum air pressure the pumps can operate at is $125 \mathrm{psig.} \mathrm{From} \mathrm{calculations,} \mathrm{the} \mathrm{pumps} \mathrm{would} \mathrm{require}$ an air supply pressure of approximately $30 \mathrm{psig}$ to pump $5 \mathrm{gpm}$ at $15 \mathrm{ft}$ discharge head.

\subsubsection{Flexibie Discharge Line}

The leak detection fipe of the secondary containment system provides the only access to the leakage accumulation area. The leakage removal pump will sit down in the leak accumulation area on the sump floor. In order to service the pump, the pump must be pulled up through the leak detection pipe from the top of the sumps. The pump, therefore, can not be permanently attached to the sump floor. Because of this, vibration or slight movement of the pump may occur. This vibration along with the length of the leak detection pipe introduces some problems with having rigid discharge piping or tubing.

Rigid discharge or outlet piping would likely require additional piping supports. The pump could not support the entire span of the discharge pipe, especially since it is not secured to the surnp floor. Pipe supports inside the leak setection pipe would be necessary, and they would make it difficult to remove the purmp and piping for maintenance and servicing purposes.

One half $\left(\frac{1}{2}\right)$ in. diameter flexible hose is recommended as the pump discharge or outlet line. The flexible line would run from the pump up through the leak detection pipe and direct discharge back into the primary containment. The flexible hose would be better suited to accommodate vibration, movement of the pump, and installation and removal. 


\subsection{Electrical and Instrumentation}

The leak detection system will be designed and operated so that is will detect any release of hazardous material waste or accumulated liquid in the secondary containment system within 24 hours (RCRA 40 CFR 265.193 (c)(3)). A leak detection device will be installed in the leak detection pipe of each sump. The detector will be able to sense the presence of fluid in the leakage accumulation area in the secondary containment (sump floor) and provide an alarming system with both a visual and an auditory alarm. The leak detection device will be serviceable from the top of the sump. One hundred twenty (120) volt electrical supply is available for the sump instrumentation. The leak detector will be able to detect $\frac{1}{2}-1$ inch leakage accumulation in the sump leakage accumulation area.

The recommended leak detection system has both visual and auditory alarm capability, and the single unit can be used for all three sumps. The leak detection system wi11 alarm at LCP-21 for sumps VES-FT-548 and VES-FT-549 and at LCP-22 for sump VES-FT-534. See Appendix $C$ for vendor information. 


\section{OPERATIONS TESTING AND QUALITY CONTROL}

WINCO personnel will be esponsible for the safety analysis evaluating the design, construction, and operation of the primary containment sump liner/leak detection systems. Preliminary and periodic testing of the leak detection alarming and pumping system will be performed at the discretion of WINCO maintenance personnel. The design will be conducive to testing. The quality control specifications are outlined in Appendix D. The quality control inspection includes but is not limited to the following (based on use of Semstone 870):

(1) Inspect the initial paint coating in accordance with coating specifications prior to primary containment installation.

(2) Visually inspect the covered grating installation on the floors and fiberglass sheet on the walls for proper anchoring.

(3) Physically inspect spaces between grating/panels Spaces are not to exceed $\frac{1}{4}$ in. at any interface, including concrete walls.

(4) Visually inspect surface preparation of fiberglass sheet to ensure that all glaze is removed and that the profile is similar to rough sandpaper.

(5) Visualiy inspect that all corners have received a proper radius with Semstone ${ }^{\circledR} 805$ Flexible Epoxy prior to proceeding with lining application of Semstone ${ }^{\circledR} 870$.

(6) Visually inspect completed lined pit. Reasons for rejection are as follows:

A. Pinholes in lining.

B. Uncured material.

C. Foreign inclusions in cured lining.

D. Inadequate thickness.

E. Use of materials not authorized in specifications.

F. Exposed reinforcement/unwet mat.

G. Wrinkles or hollow spots in lining.

H. Unauthorized variance from the specifications.

(7) The new sump liner will be vacuum box tested for leaks.

(8) The sump liner will be filled and monitored for leaks. 


\section{EQUIPMENT DESCRIPTION}

The major components and associated price estimations recommended for this project design are provided in Table 2. This estimation does not include any manhours for labor, training, inspection, safety, design, or reviews.

Table 2. Cost Estimations per Component.

\begin{tabular}{||l|l|l|l|}
\hline & VES-FT-548 & VES-FT-549 & VES-FT-534 \\
\hline Air Operated Pump & $\$ 840$ & $\$ 840$ & $\$ 840$ \\
\hline $\begin{array}{l}\text { Flexible Discharge hose } \\
\left(\frac{1}{2} \text { in.) }\right.\end{array}$ & $\$ 130$ & $\$ 220$ & $\$ 100$ \\
\hline Air Supply Line ( $\frac{1}{\text { in.) }}$ & $\$ 30$ & $\$ 40$ & $\$ 70$ \\
\hline $\begin{array}{l}\text { Air Supply Steel Pipe and } \\
\text { Fittings }\end{array}$ & $\$ 80$ & $\$ 80$ & $\$ 60$ \\
\hline Leak Detector and alarm & $\$ 600$ & $\$ 600$ & $\$ 800$ \\
\hline $\begin{array}{l}\text { Flexible Hose Connect, } \\
\text { fittings, valves }\end{array}$ & $\$ 60$ & $\$ 60$ & $\$ 60$ \\
\hline Paint Sealant & $\$ 160^{\mathrm{a}}$ & $\$ 290^{\mathrm{a}}$ & $\$ 180^{\mathrm{a}}$ \\
\hline $\begin{array}{l}\text { Secondary Containment } \\
\text { System }\end{array}$ & $\$ 2,440^{\mathrm{a}, \mathrm{b}}$ & $\$ 4,220^{\mathrm{a}, \mathrm{b}}$ & $\$ 2,670^{\mathrm{a}, \mathrm{b}}$ \\
\hline $\begin{array}{l}\text { Concrete Cutting for } \\
\text { Leakage Accumulation }\end{array}$ & $\$ 1,500$ & $\$ 1,500$ & $\mathrm{~N} / \mathrm{A}$ \\
\hline \begin{tabular}{l} 
Total \\
\hline
\end{tabular} & $\$ 5,840$ & $\$ 7,850$ & $\$ 4,780$ \\
\hline
\end{tabular}

a. See Appendix E. for paint sealant and secondary containment system material cost est imate calculations. Note, these costs are only approximations made from avallable information.

b. For secondary containment system cost estimations, Sentry Polymers, Inc. lining system was used. This estimate includes, grating, panels, fiberglass, Semstone 870 chenical resistant coating, $1 \mathrm{ft}$ diameter leak detection pipe, and Senstone 8084 primer. Hilti Anchors were not included in this est imate. 


\section{CONCLUSIONS}

The recommended secondary containment design installs a chemical resistant lining system. The recommended lining system installation will be relatively inexpensive and result in minimum down time of sump operations. It will also be easier to install than a stainless steel liner considering the confined space and various piping obstacles present in each sump.

The secondary containment/leak detection system design satisfies the RCRA 40 CFR 265.193 requirements for hazardous material containments. It provides a leak detection and leak removal system via a lea! detection pipe and provides for efficient leakage accumulation on the secondary containment (sump) floor. A space between the secondary containment floor and the primary containment liner allows leaked liquids to collect. The liner is not bunded directly to the sump walls. This provides a separation between the primary containment and secondary containment allowing liquids leaked from the primary containment (liner walls) to flow to the secondary containment floor for detection and removal. As mentioned, the currently recommended primary containment material (Semstone ${ }^{\circledR}$ ) is being tested for its chemical inertness. Alternative primary containment liner materials are being investigated in the event the Semstone ${ }^{\circledR}$ lining materials are found unsuitable.

Conceptual designs have been made using the available information collected from drawings, conversations, and site visits. Additional detail, especially for sump VES-FT-534, will be necessary for the Title II designs. 


\section{APPENDIX A.}

Resource and Recovery Act (RCRA)

40 Code of Federal Regulations (CFR) 265.193

Containment and detection of releases. 
written statements by those persons required to certify the design of the tank system and supervise the installa. tion of the tank system in accordance with the requirements of paragraphs (b) through ( $f$ ) of this section to attest that the tank system was properly designed and installed and that repairs. pursuant to paragraphs (b) and (d) of this section were performed. These written statements must also include the certification statement as required in $\$ 270.11$ (d) of this chapter.

(Information collection requirements contained in paragraphs ( $\mathrm{g}$ ) and ( $\mathrm{g}$ ) were $\mathrm{ap}$ proved by the Olflce of Management and Budget under control number 2050-0050)

[51. FTR 25479. July 14, 1986; 51 FR 29430 , Aug. 15, 1986]

\subsection{Conitainment and detection of releases.}

(a) In order to prevent the release of hazardous waste or hazardous constituents to the environment, secondary containment that meets the requirements of this section must be provided (except as provided in para. graphs $(f)$ and $(g)$ of this section):

(1) For all new tank systems or components, prior to their being put into service:

(2) For all existing tanks used to store or treat EPA Hazardous Waste Nos. F020, F021, F022, F023, F026, and F027, within two years after January 12. 1987:

(3) For those existing tank systems of known and documentable age, within two years after January 12. 1987, or when the tank systems have reached 15 years of age, whichever comes later

(4) For those existing tank system for which the age cannot be docu. mented, within eight years of January 12, 1987; but if the age of the facility is greater than seven years, secondary containment must be provided by the time the facility reaches 15 years of age, or within two years of January 12. 1987, whichever comes later, and

(5) For tank systems that store or treat materials that become hazardous wastes subsequent to January 12, 1987 , within the time intervals required in paragraphs $(a)(1)$ through $(a)(4)$ of this section, except that the date that a material becomes a hazardous waste must be used in place of January 12. .1987.

(b) Secondary containment systems must be:

(1) Designed, installed, and operated to prevent any migration of wastes or accumulated liquid out of the system to the soil, ground water, or surface water at any time during the use of the tank system: and

(2) Capable of detecting and collecting releases and accumulated liquids until the collected material is removed.

(c) To meet the requirements of paragraph (b) of this section. secondary containment systems must be at a rainimum:

(1) Constructed of or lined with materials that are compatible with the maste(s) to be placed in the tank system and must have sufficient strength and thickness to prevent failure due to pressure gradients (includ. ing static head and external hydrological forces), physical contact with the waste to which they are exposed, climatic conditions, the stress of installa. tion, and the stress of daily operation (including stresses from nearby vehic. ular traffic):

(2) Placed on a foundation or base capable of providing support to the secondary containment system and resistance to pressure gradients above and below the system and capable of preventing failure due to settlement. compression or uplift:

(3) Provided with a leak detection system that is designed and operated so that it will detect the fallure of either the primary and seconciary containment struccure or any release of hazardous waste or accumulated liquid in the secondary containment system within 24 hours, or at the earllest practicable time if the existing detection technology or site conditions will nor allow detection of a release within 24 hours:

(4) Sloped or otherwise desigred or operated to drain and remove llquids resultirig from leaks, spllls, or precipitation. Spilled or leaked waste and accumulated precipitation must be removed from the secondary containment system within 24 hours, or in as timely a manner as is possible to prevent harm to buman health or the en- 


\subsection{Sump Liner Design}

ssed, Sentry Polymers, Inc. provide secondary containnent liner These systems are constructed of Semstone ${ }^{\circledR}$ coater products and are le to this project application. The Semstone liner materials are allowing leaked materials to flow between the liner and the secondary containment (sump concrete) walls.

A leak detection/removal pipe (FRP) would be installed to provide access to the leakage accumulation area on the secondary containment floor. The pipe will be approximately $1 \mathrm{ft}$. in diameter allowing adequate space for a small pump and a leak detection device to be placed. The pipe will extend above tha liner probably to the top of the sumps in the case cif sumps VES-FT-548 and VES-FT -549. (f) Anclllary equipment must be pro.
vided with full secondary containment vided with full secondary containment
(e.g. trench. jacketing, double-walled hs (b) and (c) of this section except for:

(1) Aboveground piping (exclusive of nanges, joints, valves, and connecthons) that are visually inspected for leaks on a daily basis: and welded connections, welded joints, ally inspected for leaks on a daily (3) Sealless or magnetic coupling pumps and sealless valves, that are vis basis; and

(4) Pressurized aboveground piping systems with automatic shut-off devices (e.g., excess flow check valves, of pressure actuated shut-ofices, loss that are visually inspected for leaks on a daily basis.

(g) The owner or operator may obtain a variance from the require. ments of this Section if the Regional demonstration by the owner or opera. tor. either that alternative design and operating practices, together with lomigration of hazics. will prevent the ardous constituents into waste or haz. water or surface water at least as fectively as secondary containmen during the active life of the tank lease that does migra to or a re. water or surface mater to groun present or potential hazard will b posed to human health or the environ may not, underground tank system cord not, per a demonstration in a section. be exempted from the secon ary containment requirements of this section. Application for a variance a allowed in paragraph $(g)$ of this secthe does Dot waje compliance wit new tank systems. (1) in deciding whether to grant a variance based on a demonstration of equivalent protecwater, the Regional Administrator will
consider: (i) The nature and quantity of the
waste:
(ii) The proposed alternate design (iii) The hydrogeologic setting of the soils between the tank system and round water, and (iv) All other factors that would in haence the quality and mobillty of the tial for them to migrand the poten water or surface water. (2) In deciding whether to grant a
variance, based on a demonstration o no substantial present or potential hazard, the Regional Administrator (i) The potential adverse effects round water, surface water, and land (A) The physical and chemical char. acteristics of the waste in the char. ystem. including its potential for mi(B) The hydrogeological characteris tics of the facility and surrounding (C) The potential for health risks
caused by humarl exposure to waste (D) The potential for damage to aldife, crops, vegetation, and physi (E) The persistence and permanence (ii) potential adverse effects: release on ground-warer exts of a taking into account:(A) The quantity and quality of
ground water and the direction of and withdrawa rates of water in the area.
(C) The current and fut're uses of
ground water in the area and (D) The existing quality of ground
(D) water, Including other sources of contamination and their cumulative impact on the ground-water quality; a release on suriace water quality. taking into account: ground water anantity and quality of ground-water flowd the drection of (B) The patterns of rainfall in the 373
$15160 /$ WIL BuyLine 5791

\section{I'S SUPERSAVER AIR DISTRIBUTION SYSTEM}

n pump incorporates a redesigned "state-of-the-art" air
m. which provides up to 13 percent greater pumping cam. Which provides up to
ed air consumption averaging over 10 percent across the
ce range. This redesigned system tocuses on optimizing ce range. This redesigned system focuses on optimiz
amically tuned ports and passageways minimize tur1: reducing internal energy losses, and maximizing energy
ifd being pumped. Casting techniques, such as die casting id being pumped. Casting techniques. such as die casting
Iding, allow for the design of streamiled contours and proIding, allow for the design of streamlined contours and pro-
in surfaces, providing a significant reduction of friction of
flow. further reducing the amount of pressure required to in sur. further reducing the amount of pressure required to
flowantity of liquid. Lower pressures mean lower energy con. ating principles and basic structure of the Wilden air

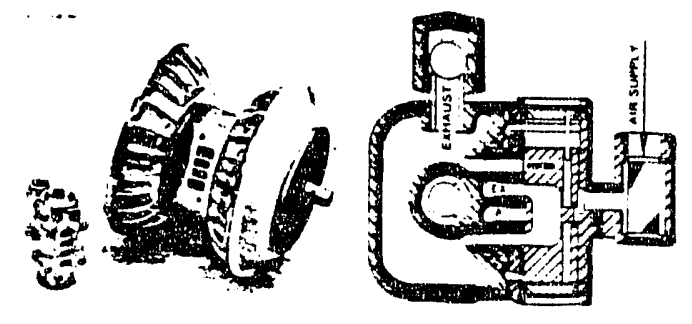

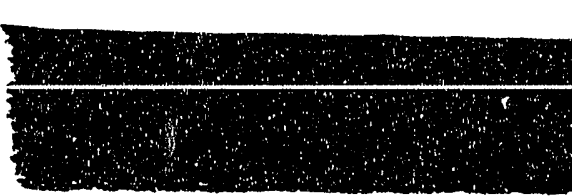

PHONE (213) $984-\$ 380$

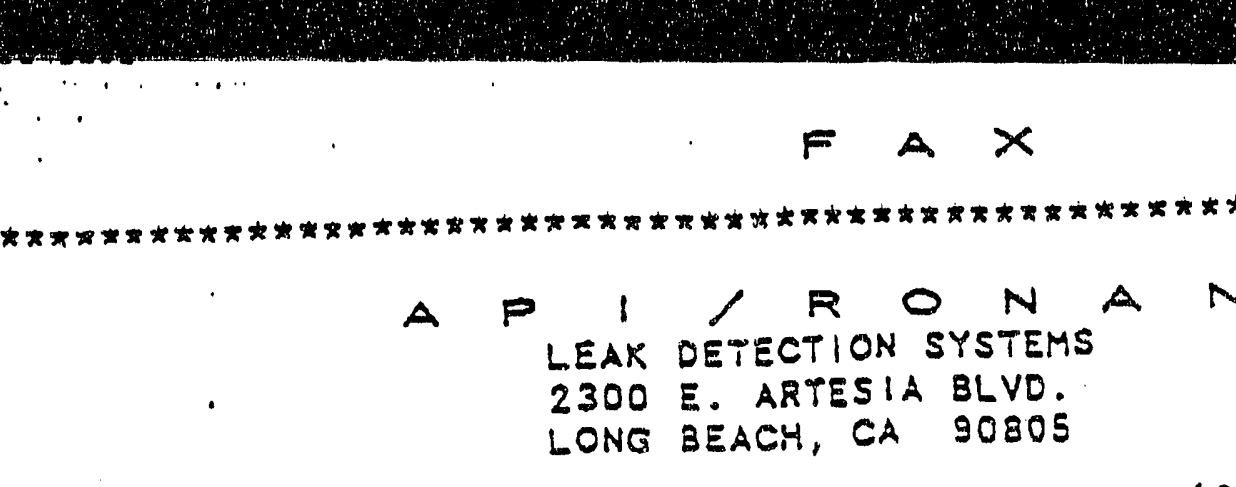

FAx $(213) 984-5300$ 
, sump on the south side. The base of the lowest weir iroximately $37 \mathrm{in.} \mathrm{from} \mathrm{the} \mathrm{top} \mathrm{of} \mathrm{the} \mathrm{sump.} \mathrm{The} \mathrm{liner,} \mathrm{therefore,} \mathrm{will}$ xtend approximately six inches above this weir. The liner depth will se approximately $11 \mathrm{ft}$ measured from the sump floor. The liner will approximately $300 \mathrm{ft}^{2}$ of sump concrete surface area.

the liner will be sealed to the concrete surface around the top and in ir area. As with sump VES-FT-548, a pump and instrumentation are a on the metal sump cover. These items extend down into the sump and it to be altered if at all possible. Sump VES-FT-549 configuration is ied in Figure 1. See Appendix $D$ for specifications.

\section{SECTION $\rightarrow$}

Figure 1. Sump VES-FT-548 and Sump VES-FT-549. (With Secondary Containment/Leak Detection System)

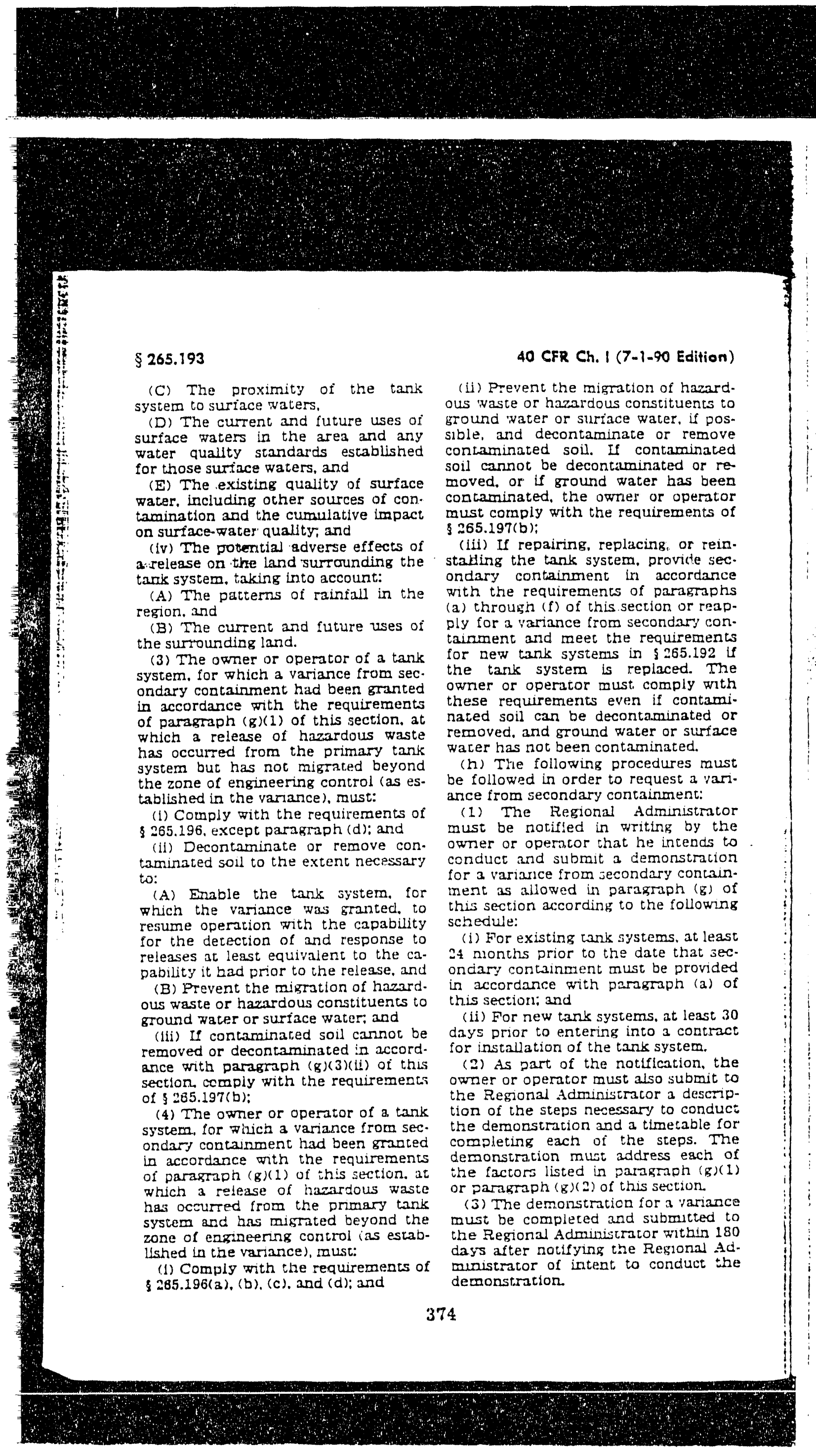

Environmental Protection Agency

(4) The Regional Administrator will lnform the public, through a newspa. per notice, of the availability of the demonstration for a variance. The weekly major local newspaper of gen. eral circulation and shall provide at
least 30 days from the date of the notice for the public to rewlew and also will hold a publtc hearing, in re sponse to a request or at his own discelaht clarify one or more is hearing cerning the demonstration for a variance. Public notice of the hearing will be given at least 30 days prior to the at the same time as notice of the portunity for the public to review and comment on the demonstration. These (5) disapprove the request for a variance within 90 days of receipt of the demonstration from the owner or perator and win hollfy in whiting the who submitted written comments or requested notice of the variance decision. If the demonstration for a varisufficiant inforte or does not include period will begin when the Regional Administrator receives a complete tion necessary to make a final determination. If the public comment period in paragraph $(h)(4)$ of this section is
extended, the 90 -day time period will be similarly extended.
(1) All tank systems. until such time as secontank systems. until such time requirements of this section ed, must comply with the following. tanks. a leak test that meets the requirements of $\$ 265.191$ (b) (5) must be conducted at least annually (2) For other than non-enterable unfor all ancillary scribed in paragraph (i)(1) of this sec. tion, or an intemal inspection or other exy an inde sional engineer that addresses cracks. leaks, corrosion, and erosion must be
18

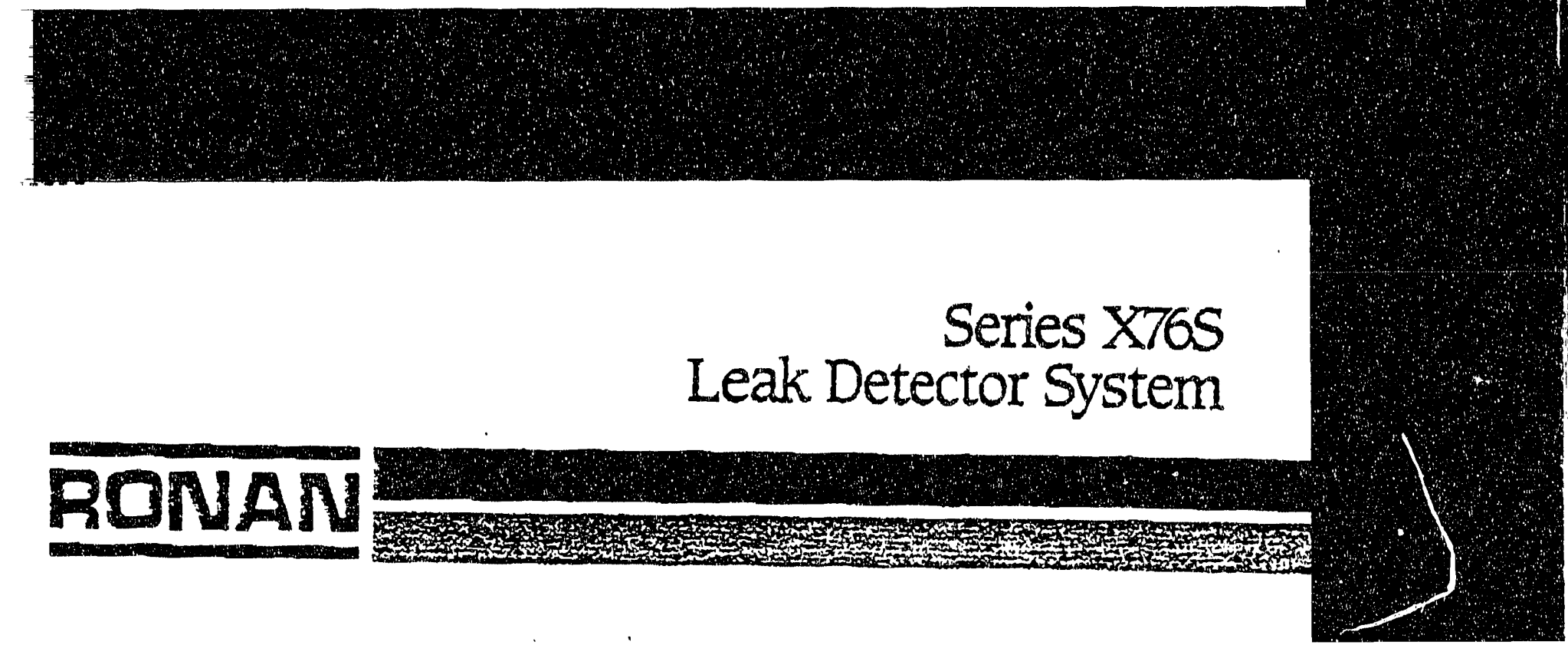

conducted at lesst annually. The or operstor must remove the ary, waste from the tank, if neces. ternal tank surfaces to be assessed. Nork The practices described in the
merican Petroleum Institut (API) Pubuguipment. for Inspection of Refioing

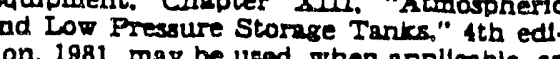

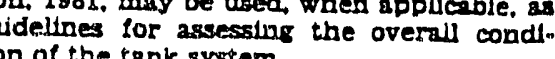
(3) The owner or operator must record of the results of the assese ments conducted in accorclance with paragraphs (1)(1) through (1)(3) of this (4) If a tank system or component is a result of the leak paragraphs (1)(1) through (i)(3) of must comply with the requirements of Unformation collection requirements contained in paragraphs (c)-xeq) and ( ( ) f)-(1) were (51 FR 25479. July 14, 1986: 51 FR 29430 [51 FR 25479. July 14, 1986: 51 FR 29430
Aug. 15. 1986. as amended at 53 FR 34087 .
Sept. 2. 1988) as (a).194 General operating requiremente. (a) Hazardous wastes or treatment stem if they could cause the tank 列y containment system the secondary containment system to rupture. (b) The owner or operator must use appropriate controls and practices to or secondary containment systems (1) include at a minimum: (1) Spill prevention controls (e.g (2) Overfill prevention controls (e.g. alarms. automatic feed cutoff, or bross to a standby $\tan k$ ): and ficient free oard in uncovered tanks to preven vertopping by wave or wind action or
precipitation. (c) The owner or operator must
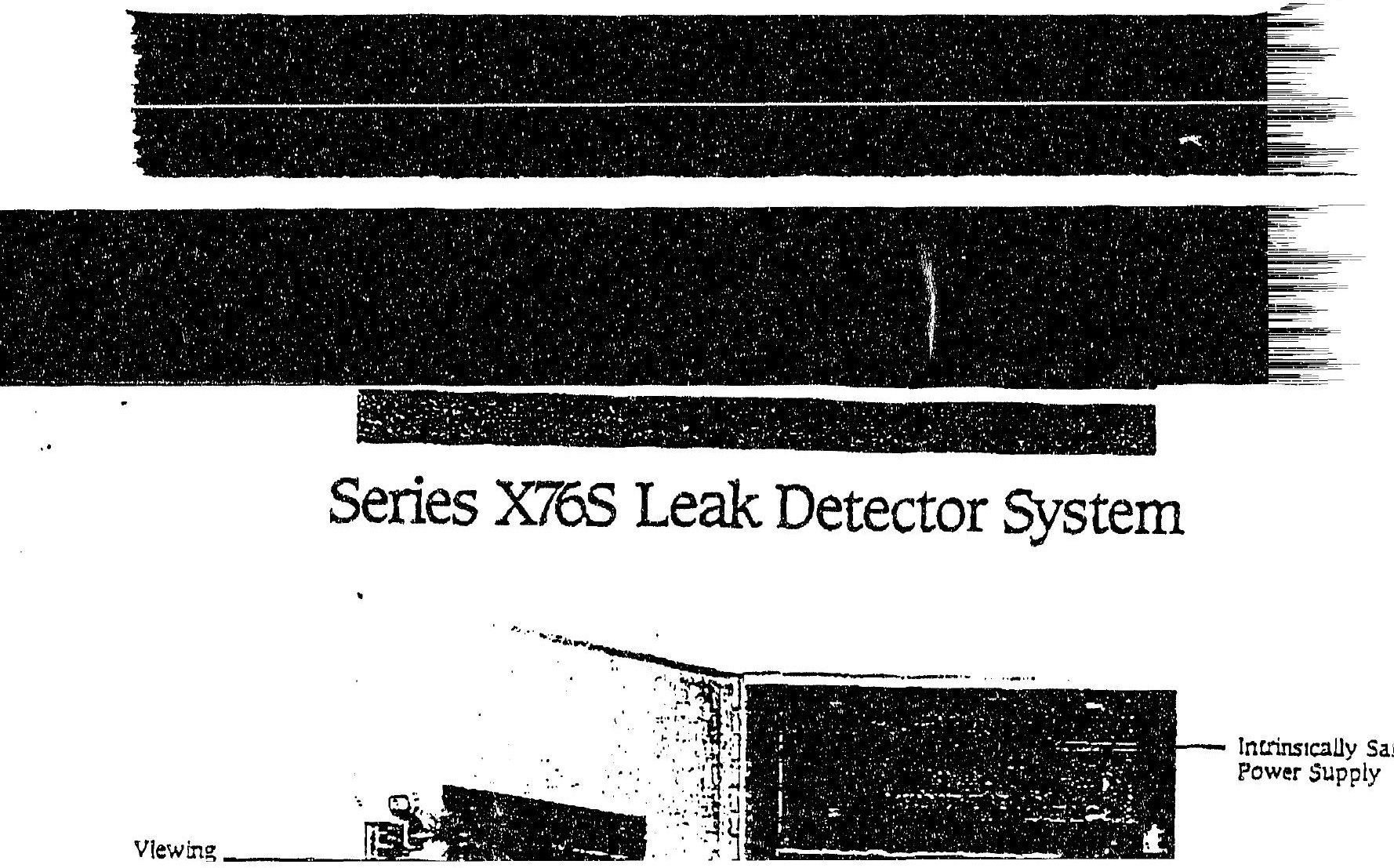
APPENDIX B.

WINCO Safety Approval for

Secondary Containment System. 
TO: Jim Downes, N\&IS

From: T.H. Waite Ththast

April 29, 1992

Subject: Use of Semstone 870

Permission is requested to use semstone 870 , manufactured by sentry polymers, Inc. It is to be used for the fabrication of secondary containment liners FAST-FT-534/548/549.

The sumps being lined are located below grade level, and require secondary containment due to the liquids that are collected in the sumps. Semstone 870 is compatible with the chemicals that are collected in these sumps. No other coatings of this type have been found that are compatible with the chemicals being collected.

The MSDS sheets for semstone 870 are attached. It shows that one of the components, Part A, contains styrene, which is a potential carcinogen.

Your permission to use Semstone 870 for this particular application is requested. If there are any questions, please contact me at 6-3699.

Permission is given to use semstone 870 for secondary containment for the past sumps.

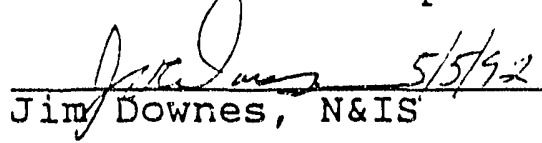




\section{APPENDIX C.}

Vendor Information:

(paint sealants and liner secondary containment materials, air operated pumps, and leak detection devices) 


\section{TECHWICAL EULHEIM: \\ Septemither 1990}

\section{DESCRIPTION AND USES:}

SEMSTONE 870 is a Sentry's vinyl ester lining system for protecting concrete.

It is normally chosen for its exceptional resistance to certain difficult chemicals, such as nitric acid, acetic acid, chlorine and hypochlorites.

SEMSTONE 870 is applied by roller or brush, reinforced with Sentry's fiberglass scrim clo $\ldots$, and aggregate filled by the broadcast method, to yield a system with a finished thickness of approxirnately $1 / 8$ inch.

\section{PACKAGING/COVERAGE:}

SEMSTONE 870 is available in 1 gallon and 5 gallon units. Each unit consists of a premeasured Part $A$ component and a premeasured Part $B$ component. A bagged Part $C$ thixotropic agent is added for work on vertical surfaces.

Coverage rates are affected by the condition of the surface being coated. Over new concrete that has been properly prepared and primed, figure THEORETICAL coverage rates at 20 square feet per gallon. FoI PRACTICAL coverage, make necessary allowances for condition of the substrate. working conditions, waste, spillage, etc.

Allow one-half pound of aggregate per square foot, on horizontal surfaces. Wse only clean, dry bagged 20/40 mesh silica aggregate containing not less than $97.5 \%$ silicon dioxide (such as that produced by the Otiawa Silica Company, Ottawa, Illinois.)

\section{SEMSTONE 옹요}

\author{
Reinforced Vinyl Ester \\ Coating/Lining System
}




\section{WORKING PROPERTIES:}

Pot Life @ 75 F 30 minutes Cure Time@ $75^{\circ} \mathrm{F}$ :

(significantly less at elevated temperatures or in direct sunlight) Foot traffic Light vehicular traffic 12 hrs. Chemical service 24 hrs. Primer $48 \mathrm{hrs}$.

Color SEMSTONE 8084 Primer Gray

\section{RELATED AND ANCILLARY PRODUCTS:}

SEMSTONE 8084 Vinyl Ester Primer

SEMSTONE 8084 Vinyl Ester Putty

SEMSTONE 884 Vinyl Ester Polymer Concrete

SEM-CRETE Rapid Hardening Underlayment Mortar

Refer to separate data sheet on each product for its uses, application instructions, etc.

\section{STORAGE AND SHELF LIFE:}

Keep SEMSTONE 870 components tightly sealed in their original containers until ready for use.

Store at $50^{\circ} \mathrm{F} \cdot 60^{\circ} \mathrm{F}$, out of direct sunlight.

Part A is flammable. Do not store near open flame, sparks or heat.

It is critical that the scrim cloth be kept in dry storage at all times. Otherwise, it may absorb atmospheric moisture and be rendered unusable with the system

Use SEMSTONE 870 within three months of date of manufacture. Refer to batch number on label for date of manufacture.

Due to their limited shelf lives, Sentry will not accept returns of vinyl ester products. Please order carefully. 


\section{CHEMICAL RESISTANCE GUIDE}

This guide is intended as an aid in determining the potential usefulness of SEMSTONE 870 as a protective barrier against chemical exposure. Each application should be evaluated according to its particular circumstances and conditions.

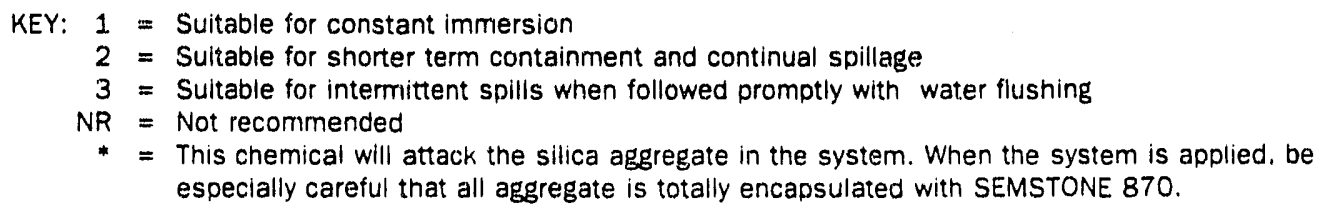

RATING

Acetic Acid, $10 \%$

Acetic Acid, 30\%

Acetic Acid, Glacial

Acrylic Acid, up to $25 \%$

Alum

(Aluminum Potassium Sulfate)

Alumirium Chloride

Aluminum Fluoride

Aluminum Hydroxide

Aluminum Nitrate

Aluminum Sulfate

Ammonia

Ammonium Bisulfite

Ammonium Chloride

Ammonium Hydroxide

Amrnonium Nitrate

Ammonium Sulfate

n-Amyl Alcohol

Aniline

Barium Chloride

Barium Hydroxide

Barium Sulfate

Barium Sulfide

Benzene

Benzene Sulfonic Acid

Benzoic Acid

Black Liquor. Pulp Mill

Bleach t.iquor, Pulp Mill

Boric Acid

Brine

Bromine, Liquid

Bromine Gas (Dry \& Wet)

n-Butyl Alcohol

Butyl Cellosolve Solvent

n-Butyric Acid

Cadmium Chloride

Calcium Chloride

Calcium Hydroxide

Calcium Hypochlorite

Calcium Nitrate

Calcium Sulfate

Calcium Sulfite

Carbon Dioxide Gas

Carbon Dissulfide

Carbon Tetrachloride

Chlorine Dioxide

Chlorine Gas (Dry \& Wet)

Chlorine Water

Chlorobenzene

Chloroform

Chromic Acid, 15\%

Chromic Acid, $50 \%$

Citric Acid
1

2

1

1

1*

2

1

2

1

1

2

1

2

NR

1

2

1

2

1

1

1

NR

2

3

2

1

1

2

$1 *$

1

2

1

NR

3

1

1

1

NR

NR

2

NR
Copper Chloride

Copper Cyanide

Copper Nitrate

Copper Sulfate

Com Oil

Cyclohexane

Cyclohexanol

Cyclohexanone

Dichlorobenzene

Ethyl Benzene

Ethyl Chloride

Ethylene Dichloride

Ethylene Glycol

Fatty Acids

Ferric Chloride

Ferric Nitrate

Ferric Sulfate

Ferrous Chloride

Fluosilicic Acid

Formaldehyde

Formic Acid

Fuel Oil

Glycerine

Heptane

Hexane

Hydrobromic Acid

Hydrochloric Acid. 15\%

Hydrochloric Acid. 37\%

Hydrofluoric Acid

Hydrogeri Peroxide

Hydrogen Sulfide

Jet Fuel

Kerosene

Lactic Acid

Lauryl Chloride

Lead Acetate

Linseed Oil

Lithium Bromide

Lithium Chloride

Lithium Hypochlorite

Lithium Hydroxide

Magnesium Bisulfite

Magnesium Carbonate

Magnesium Chloride

Magnesium Hydroxide

Magnesium Sulfate

Maleic Acid

Mercuric Cnloride

Mercurous Chloride

Methyl Chloride

Methylene Chloride

Mineral Spirits

Monochloroacetic Acid
RATING

Naphtha

Naphthalene

Nitric Acid, 5\%

Nitric Acid, 30\%

Nitric Acid. 50\%

Nitrobenzene

n-Octyl Alcohol

Olls

Oleic Acid

Oxalic Acid

Phenol

Phosphoric Acid, 50\%

Phosphoric Acid, 85\%

Phosphorous Acid

Potassium Carbonate

Potassium Chloride

Potassium Dichromate

Potassium Hydroxide

Potassium Nitrate

Silver Nitrate

Sodium Acetate

Sodium Bicarbonate

Sodium Bisulfate

Sodium Bisulfite

Sodium Carbonate

Sodium Chloride

Sodium Chlorite

Sodium Hyaroxide, 10\%

Sodium Hydroxide, 50\%

Sodium Hypochlorite.

Sodium Sulfate

Sodium Sulfide

Stannic Chloride

Stannous Chloride

Stearic Acid

Sugar/Sucrose

Sulfur Dioxide

Sulfuric Acid, 10\%

Sulfuric Acid, $50 \%$

Sulfuric Acid, 98\%

Tall Oil

Tannic Acid

Tartaric Acid

Toluene Sulfonic Acid

Trichloracetic Acid

Trichloroethylene

Trisodium Phosphate

Urea

Water, Deionized

Water, Demineralized

Water, Distilled

Zinc Chloride

Zinc Sulfate
RATING

1

1

2

NR

1

1

NR

1

1

1

1

2

1

1

1 *

1

1

1.

2 
75 da Lemhi Street.

Eoise. Idano $83700-2837$

(2C3) 323.0505

Fax No. (208) 375-9824

פ.G. \& G. OF IDAHO

Z.0. 90Z 2525

IDAEO FAIIS, ID 83415

QUOTATION

ATMENTION:

KELIY GAIIOWAY

Date: $\quad 0.4-10-92$

Quotation $\ddot{\pi}_{041092-72-6333}$

Rei:

IAARAGD PUMES

\begin{tabular}{|c|c|c|c|}
\hline item & Oty. & Descriotion & Price Faxp \\
\hline$I$. & If EACH & 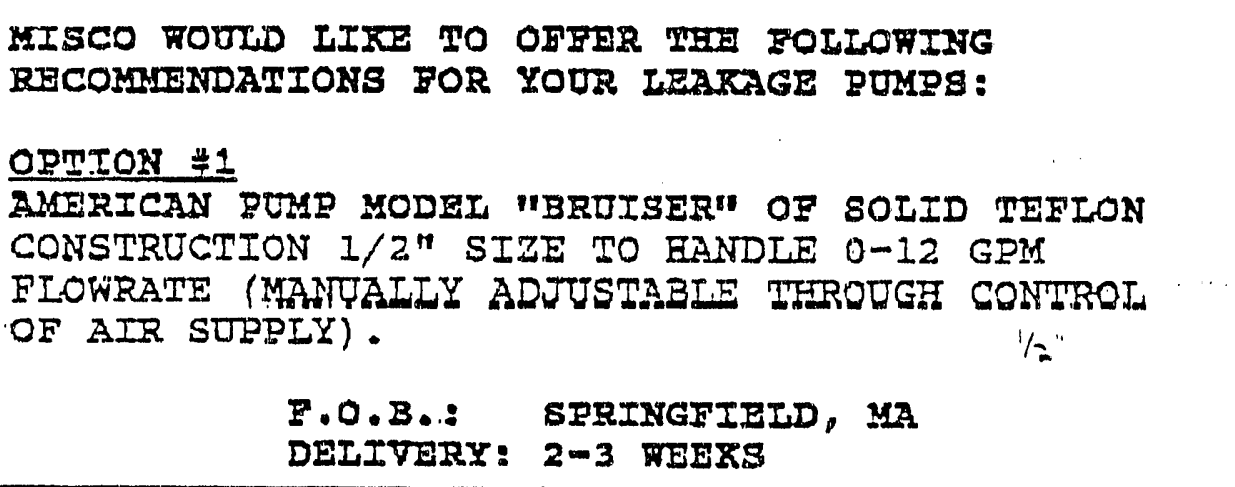 & $\$ 1,550.0$ \\
\hline 2 & 3. EACF & 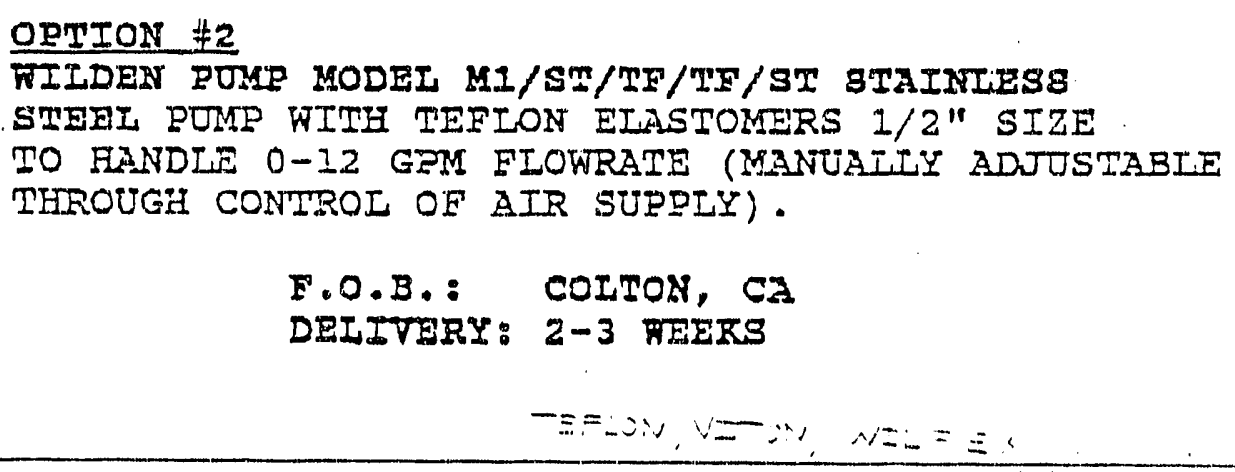 & 830.0 \\
\hline & & 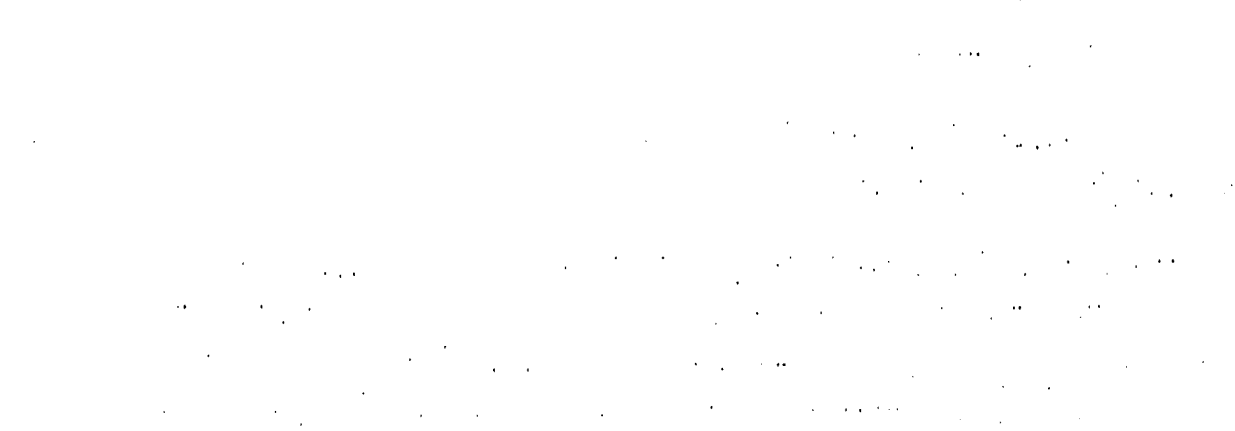 & ' \\
\hline
\end{tabular}

This quotation subject to our standard conditions of sale on the back slde of this page.

Estimated shipping date SEE PROPOSAT after receipt of acceptance of this quetailon.

F.O.B. SEL PROTOSAI

TEMTIS_ NET 30 DATS

This quotarion good for 30

days.

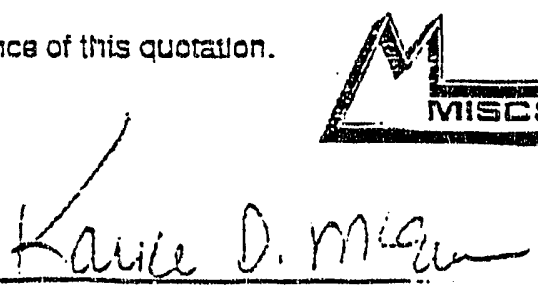




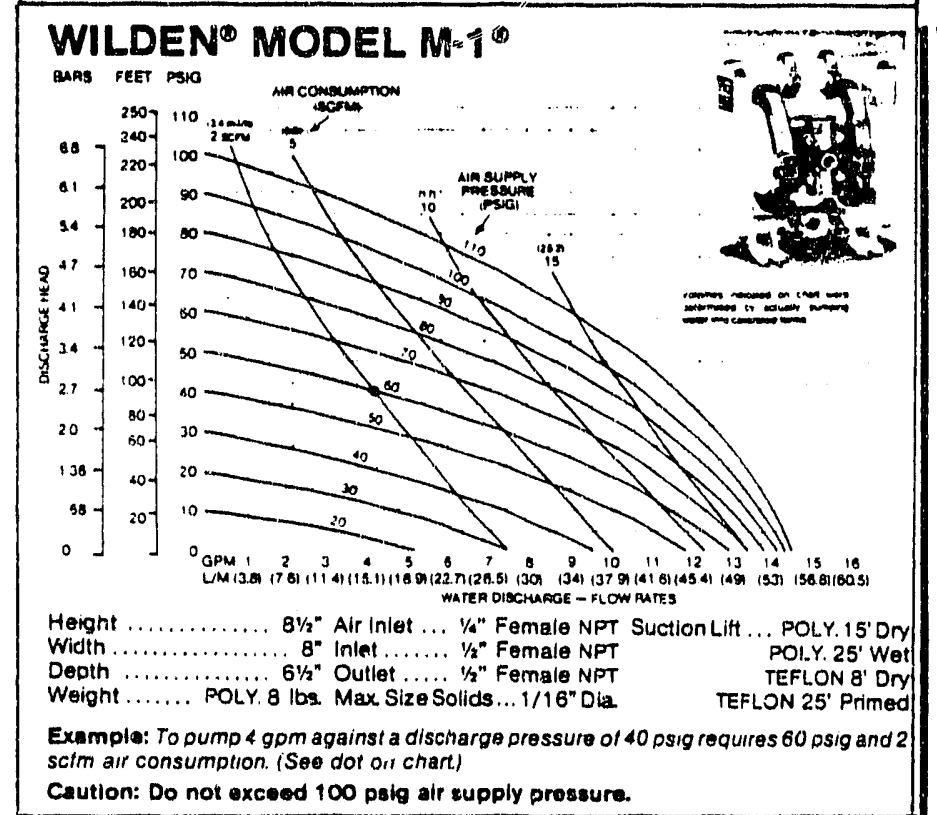

Caution: Do not exceed 100 paig air eupply prossure.

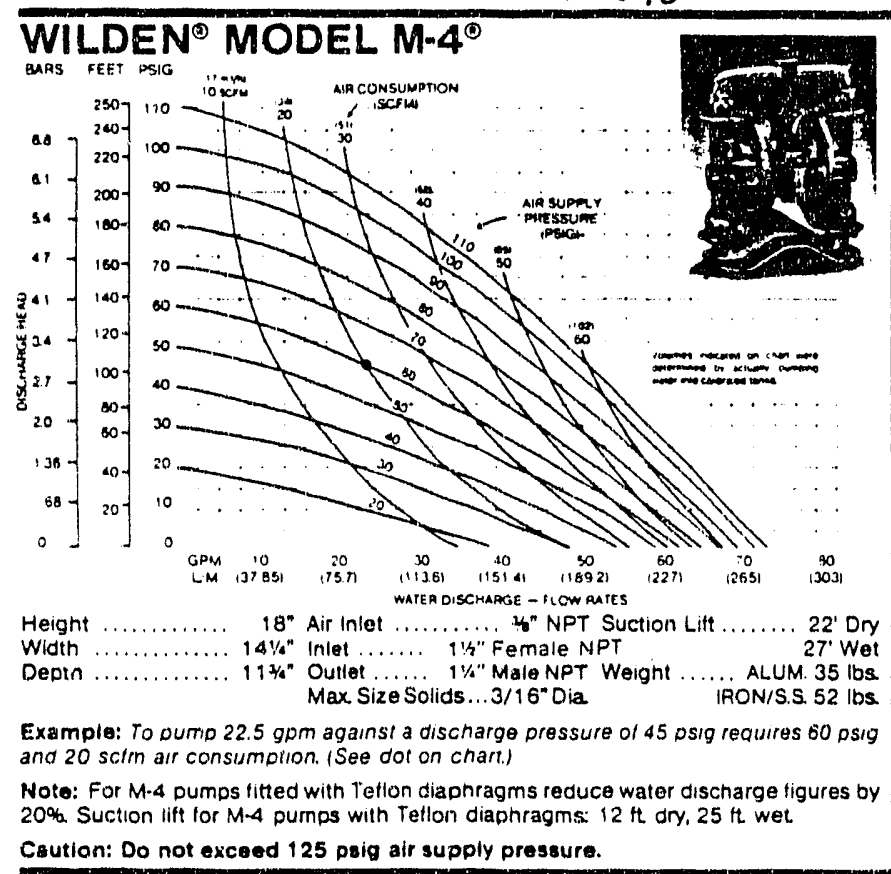

\section{WILDEN ${ }^{\otimes} \mathrm{M}^{-15^{\circ}}$}

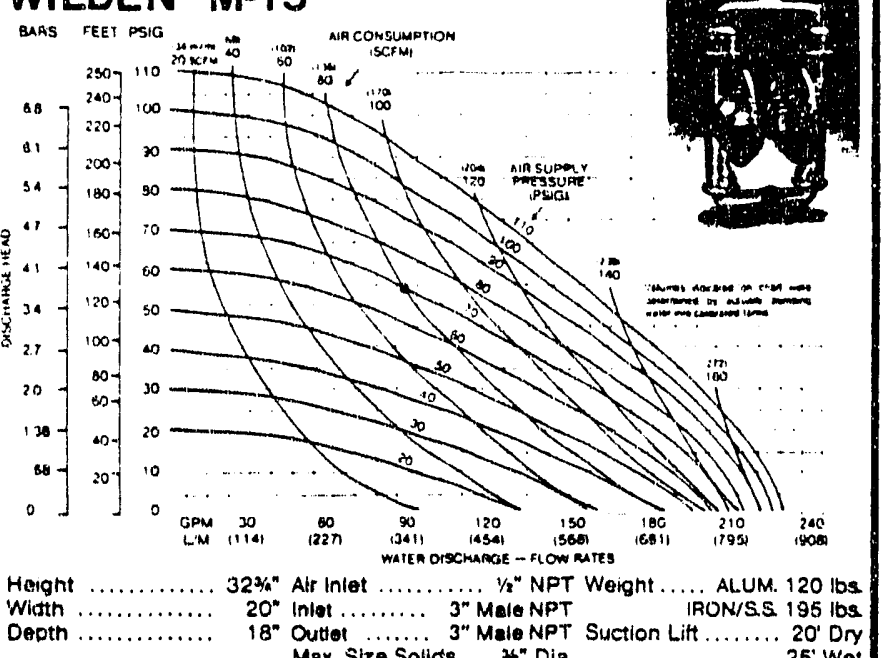

Depth .............. $18^{n}$ Outter ...... 3" Male NPT Suction Lift....... $20^{\prime}$ Dry

Example: ro pump 90 gpm against a discharge pressure of 55 psig requires 70 psig and $80 \mathrm{sefm}$ air consumption. (See dot on chart)

Nete: For M-15 pumps fitted win Teflon diaphragms reduce water orischarge figures by $20 \%$ Suction litt for M-15 pumps with Teflon diaphragins: $12 \mathrm{~h} \mathrm{dry,} 18 \mathrm{th}$ wet

Caution: Do not excend 125 osia eif subotv oressure.

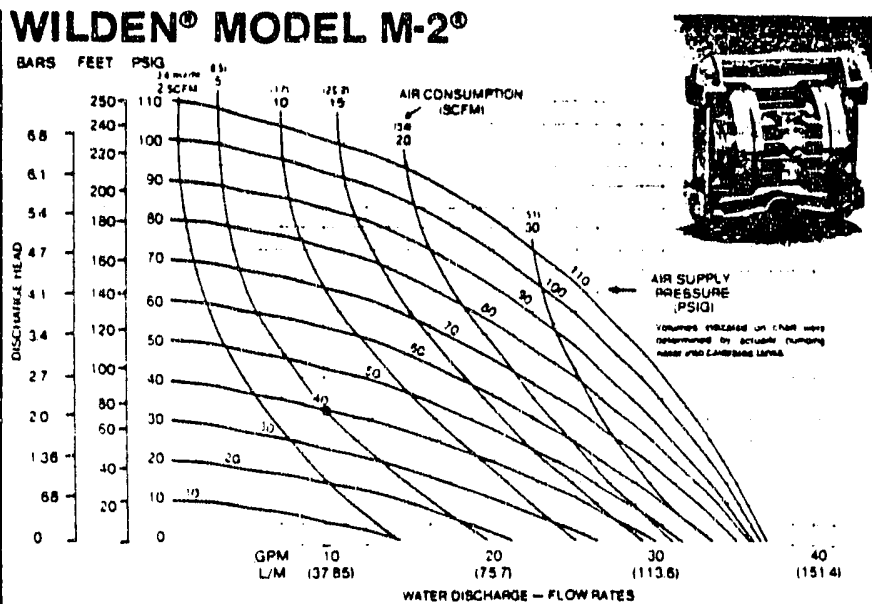

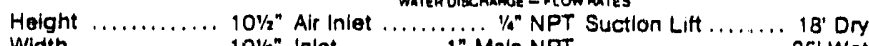

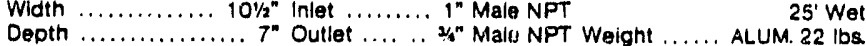
Max Size Solids ... k" Dia S.S.HASTELLOY 35 lbs. Example: To pump $10 \mathrm{gpm}$ against a discharge pressure of 35 psig requires 40 psig and 5 sctm air consumption. (Seo dot on chart)

Note: For M-2 pumps fitted with Tellon diaphragms reduce water discharge figures by 20\%. Suction lift for $\mathrm{M}-2$ pumps with Tetlon diaphragms: $10 \mathrm{ft}$. $\mathrm{dry}, 25 \mathrm{ft}$ wet Caution: Do not exceod 125 psig air supply pressure.

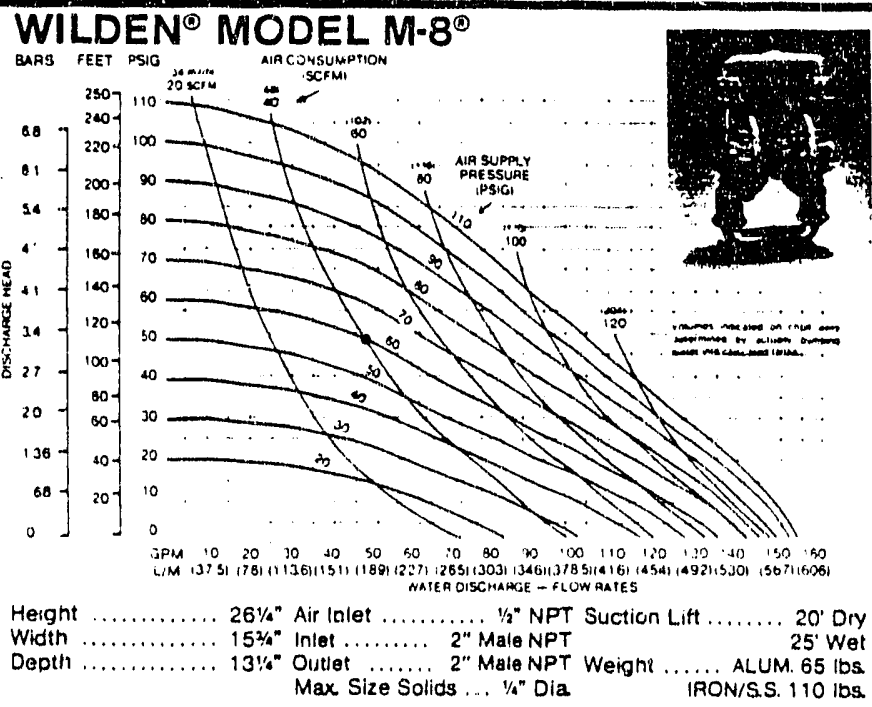

Exampla: To pumo $47 \mathrm{gpm}$ against a dischaige pressure of $50 \mathrm{ps} / \mathrm{g}$ requires $60 \mathrm{psig}$ ano 40 scim air consumption. (See dot on chart.)

Note: For $M-8$ pumps fitfed with Teflon diaphragms reduce water discharge figures by $20 \%$. Suction lift for $M \cdot 8$ pumps with Tellon diaphragms: 12 th dry, 18 it wet Caution: Do not exceed $\$ 25$ psig air supply pressure.

In addition to those pumps listed, Wilden also offers:

The model M20. This pump offers flows to $320 \mathrm{gpm}$. Available in cast iron wetted construction only. The pump is manufactured with 4" American Standard Pipe Flange, 125 lb. class. The M20 offers the same ease of maintenance as our standard purnp line.

The model M8 High Pressure Pump. This unit is capable of pumping product against $650 \mathrm{ft}$. of head pressure. Available in stainless steel wetted construction with Saniflex diaphragms only.

Please contact the factory for additional information regard. ing our new pump models.

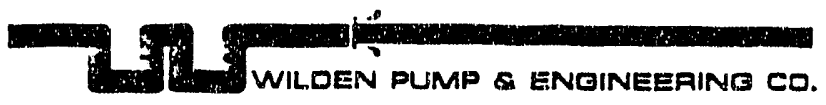

22089 Van Buren Street / P.O. Box 845

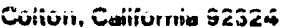

$714 / 422-1700$

Tolox: 676.452

FAX: $714 \cdot 783-2432$ 


\section{AIR OPERATED DOUBLE DIAPHRAGM PUMPS}

\section{MILDEN PUMPS ${ }^{\circ}$}

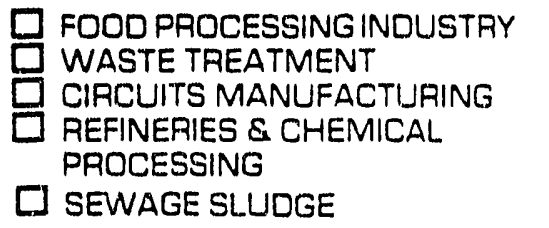

\author{
$\square$ PAINT MANUFACTURING \\ PLANTS \\ 口 ADHESIVES \& GLUES \\ $\square$ SHIPS \& MARINE \\ $\square$ CERAMIC PLANTS \\ $\square$ CARPET \& TEXTILE PLANTS
}

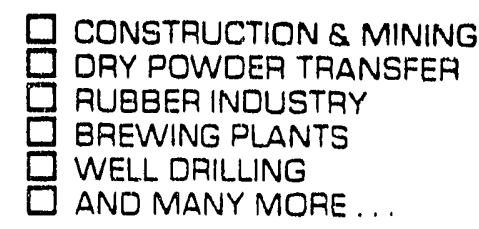

\section{COMPARISON CHART}

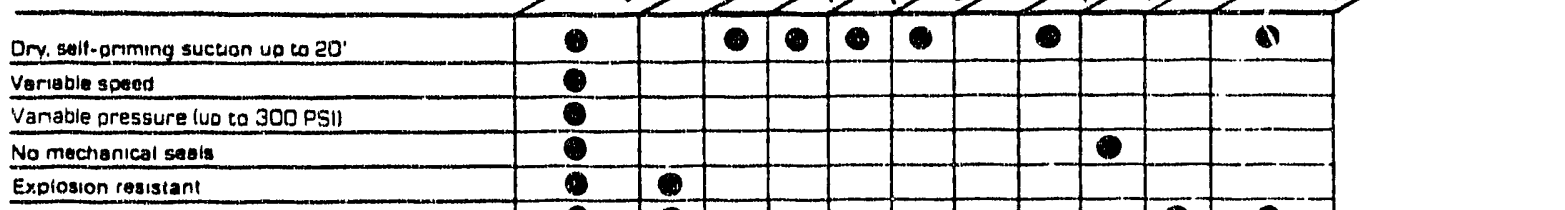

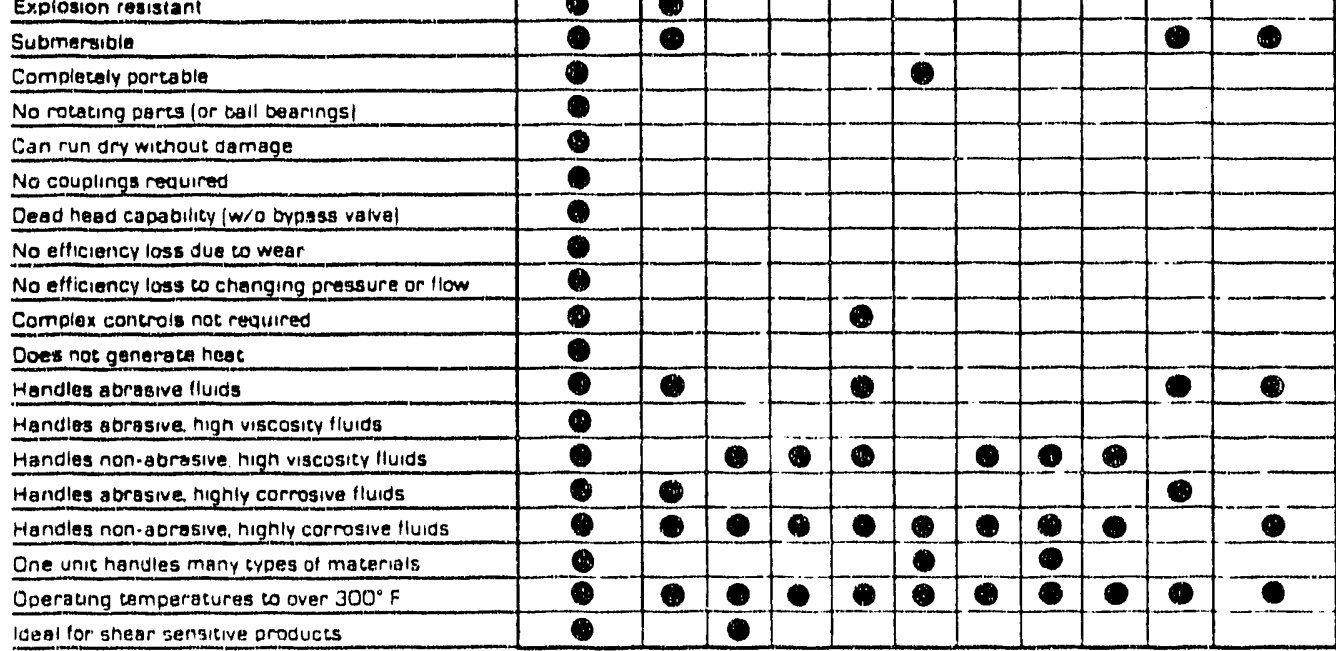

\section{THE WILDEN PUMP}

\section{HOW IT MORXS}

Compressed air is applied direcily to the liquid column separated by elastomer diaphragms. This balanced load removes the mechanical stress from the diaphragms to allow high heads and thousands of hours of diaphragm life.

The pumping volume is controlled by easy inlet air adjustments, from a few gallons per hour to over fourteen inousand gallons per hour with the same unit. $A$ by-pass valve is not required because the pump stops when discharge pressure equals air inlet pressure. The pump can also run dry indefinitely without damage. Our double diaphragm design cuts velocity through the pump to half total discharge velocity. The most abrasive slurries produce little wear effect on pump parts.

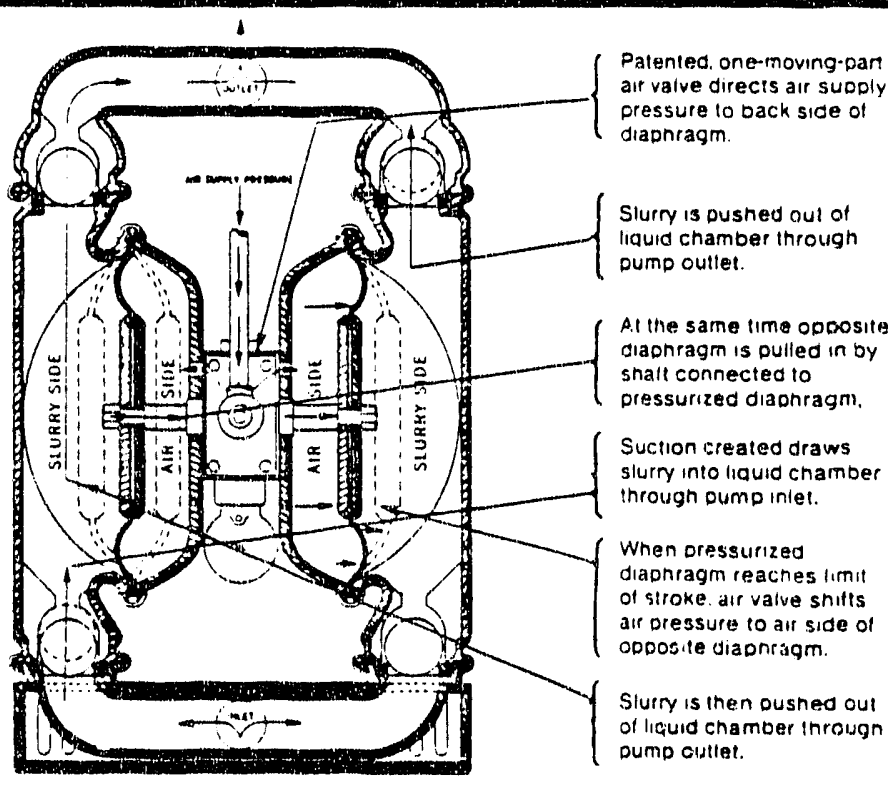




\section{WILDEN'S SUPERSAVER AIR DISTRIBUTION SYSTEM}

Every new Wilden pump incorporates a redesigned "state-of-the-art" air cistnbution system, which provides up to 13 percent greater pumping ca. pacity and reduced air consumption averaging over 10 percent across the entire performance range. This redesigned system focuses on optimizing air flow. Aerodynamically tuned ports and passageways minimize turbulence and drag, reducing internal energy losses, and maximizing energy iransier to the fluid being pumped. Casting techniques, such as die casting ard injection molding, allow for the design of streamlined contours and prorice smoother skin surfaces, providing a significant reduction of friction of Din air and fluid flow, further reducing the amount of pressure required to :ransier a given quantity of liquid. Lower pressures mean lower energy consumed. The operating principles and basic structure of the Wilden air vaive. which have provided the highest level of reliability for over 30 years, remains unchanged. We have simply made the best a little better by reengineering components unrelated to the critical shifting functions which make the Wilden valve superior to any other valve system. The ability of the valve to deliver unequaled reliability operating against a stall, or in intermittent service at minimum air supply pressures, remains unchanged.

Pre-1985 Wilden pumps can achieve these energy savings by relrolitting the existing air distribution system with the new design.
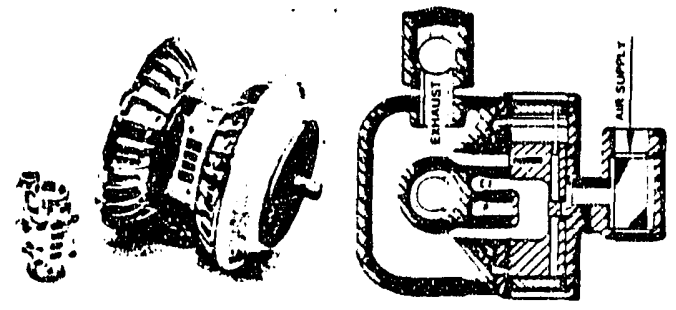

Exclusive Alr Valve - the only moving part in the unique Wilden air valve is the coated piston. The Wilden air valve is externally serviceable. Unlike many other air driven pumps. the Wilden pump does not need to be disassembled to service the air valve. Removing four bolts makes the air valve easily available for inspection or service.

\section{JSE THIS VERSATILE PUMP}

In Permanent Installations, Subrnerged Operations, Self-Priming, Fixed or Portable.

Murmenent inalailations - no foundations. no electrical contrals required. nandes sludges. slurries. acids. explosives. corasives, a clamps remove it trom permanent piping

Submerged Operntion - lor construction. industrial oumoing. nanciles mud. sand, mill scale, grout, sludges: imantweight and poriable

\section{MATERIALS AND FINISHES}

Materials of construction for wetted parts are: aluminum, class 30 cast iron, 316 stainless steel. Hastelloy $C$, injection-molded polypropylene. Tellon: PFA, and injection-molded PVDF. Nonwetted materials are: aluminum, polypropylene, with cast iron or 316 stainless steel avallable as options in some models. Diaphragms, valve balls and seats are available in: Neoprene. polyure. Inane. Buna N. EPDM, Viton. Hypalon, Saniflex " and Teflon's (TFE). All materials not available in all models, see your Wilden dealer or consult actory for specific, models. All metallic pumps excepl food models are finished in high quality, nard coat. gloss orange enamel. All metallic jumps can be specified non-painted. Models $M$ $4 . M-8$ and $M-15$ in aluminum construction can be ordered with an optional strainer to prevent oversize solids from entering the pump s inlet.

\section{WARRANTY}
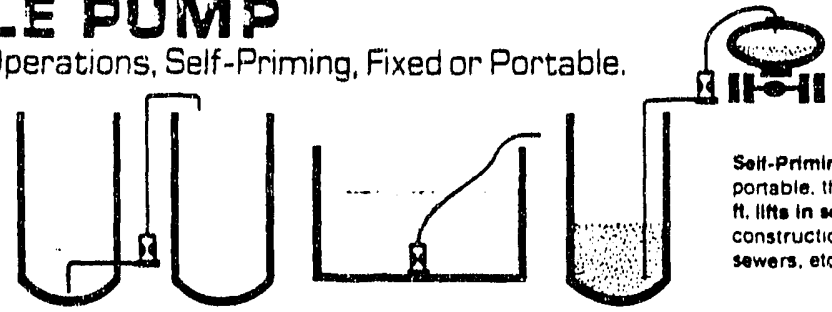

\section{SAMPLE TECHNICAL SPECIFICATION}

GENERAL DESCRIPTION:The pump shall be compressed air-operated doublediaphragm design with ball check valves. Held together with clamp bands for added security, easy maintenance, and quick inspection. Pumping action shall be controlled by an externally serviceable air valve with only one moving part. Pump shall have a (size) suction inlet anda discharge port. Pump shall be selfpriming, capable of high suction lift and able to run dry without damage.

CONSTRUCTION: Wetted parts shall be of (materiall__._. Elastomers shall be of (material) diaphragms, (materiall valve balls and (material) valve seats.

CAPACITY: Pump shall be capable of delivering _ gallons per minute at $\frac{(x)}{(x)}$ feet of discharge and $\frac{(x)}{\text { SCFM feet of suction lift, using }}$ formance charts.)

\section{AVAILABILITY}

Wilden pumps are sold through a network of qualified, authorized distributors. Wilden's distributors maintain a stock of pumps and replacement parts. Generally customers' requirements can be handled from distributor stock in a matter of days. Factory shipments generally take two to four weeks, depending upon the specific order. Current list prices are published and are available from Wilden's distributors or by request from the factory.

All pumps manufactured by Wilden Pump and Engineering Company are manufactured to the highest siandards of quality and workmanship. Every pump is hydrostatically and functionally tested and guaranteed to operate as designed and meet our published performance curves. Materials and workmanship are guaranteed for one year from start-up or two years from shipment, whichever occurs first. Flow rates were determ ined oy measurement into calibrated tanks and air consumption data was determined by the use of calibrated mass flow meters.

\section{Wilden offers mare...}

More Sizes - Five sizes with flows from 0 to 230 GPM

More Elastomer Materials - Compatibility with any chemical solution.
More Value - Lower prices and operating costs

More Performance - Higher flows
More Pump Materials - Aluminum. cast iron, 316 SS, Hastelloy C, polypropylene, PVDF, Tefloni PFA. 


\section{WILDEN'S SUPERSAVER AIR DISTRIBUTION SYSTEM}

Every riew Wilden pump incorporates a redesigned "state-of-the-art" air distribution system, which provides up to 13 percent greater pumping capacity and reduced air consumption averaging over 10 percent across the entire performance range. This redesigned system focuses on optimizing air flow. Aerodynamically tuned ports and passageways minimize turbulence and drag, reducing internal energy losses, and maximizing energy transfer to the fluid being pumped. Casting techniques, such as die casting and injection molding, allow for the design of streamlined contours and provide smoother skin surfaces, providing a significant reduction of friction of both air and fluid flow, further reducing the amount of pressure required to transfer a given quantity of liquid. Lower pressures mean lower energy consumed. The operating principles and basic structure of the Wilden air valve, which have provided the highest level of reliability for over 30 years, remains unchanged. We have simply made the best a little better by re. engineering components unrelated to the critical shifting functions which make the Wilden valve superior to any other valve system. The ability of the valve to deliver unequaled reliability operating against a stall, or in intermittent service at minimum air supply pressures, remains unchanged.

Pre- 1985 Wilden pumps can achieve these energy savings by retrofitting the existing air distribution system with the new design.
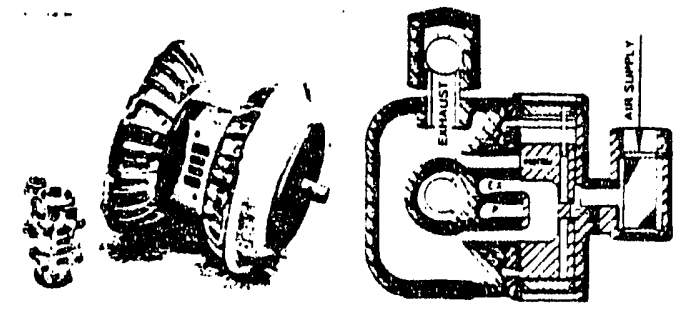

\section{USE THIS VERSATILE PUMP}

In Permanent Installations, Submerged Operations, Self-Priming, Fixed or Portable.

Pamainene Installationa - no loundations. no electrical controls required, handles sludges. slurries. acids. explosives. abrasives: 4 clamps remove 11 trom permanent piping.

Submerged Operation - lor construction industrial pumping: handles mud, sand. mul scale. grout. sludges: lightweight and portable

\section{MATERIALS AND FINISHES}

Materials of construction for wetted parts are aluminum, class 30 cast iron, 316 stainless steel, Hastelloy $C_{\text {, injection-molded polypropylene. }}$ Teflon PFA, and injection-molded PVDF. Nonwetted materials are: aluminum, polypropylene. with cast iron or 316 stainless steel available as options in some models. Diaphragrns, valve balls and seats are available in: Neoprene, polyure. thane, Buna N. EPDM, Viton, Hypalon, Saniflex" and Teflon' (TFE). All materials not available in all models, see your Wilden dealer or consult factory for specific models. All metallic pumps except food models are finished in high quality, hard coat, gloss orange enamel. All metallic pumps can be specified non-painted. Models $M$ $4, M-8$ and $M-15$ in aluminum construction can be ordered with an optional strainer to prevent oversize solids from entering the pump's inlet.

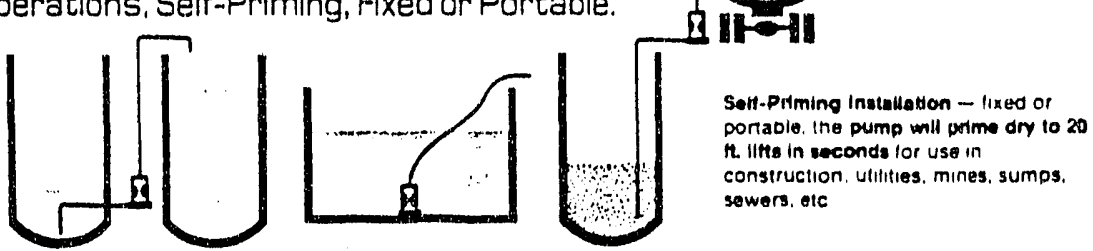

\section{SAMPLE TECHNICAL SPECIFICATION}

GENERAL DESCRIPTION:The pump shall be compressed air-operated doublediaphragm design with ball check valves. Held together with clamp bands for added security, easy maintenance, and quick inspection. Pumping action shall be controlled by an externally serviceable air valve with only one moving part. Pump shall have a (size) suction inlet anda (size) discharge port. Pump shall be self. priming, capable of high suction lift and able to run dry without damage.

CONSTRUCTION: Wetted parts shall be of Imateriall_. Elastomers shall be of (material) - diaphragms, (material) valve balls and $\begin{gathered}\text { (material) } \\ \text { - valve }\end{gathered}$ seats.

CAPACITY: Pump shall be capable of delivering $(x)$ gallons per minute at $\frac{(x)}{(x)}$ PSI and $\frac{(x)}{(x)}$ feet of discharge and $\frac{1}{\text { SCFM of compressed air. (Refer to per- }}$ formance charts.)

\section{AVAILABILITY}

Wilden pumps are sold through a network of qualified, authorized distributors. Wilden's distributors maintain a stock of pumps and replacement parts. Generally customers' requirements can be handled from distributor stock in a matter of days. Factory shipments generally take two to four weeks, depending upon the specific order. Current list prices are published and are available from Wilden's distributors or by request from the factory.

\section{WARRANTY}

All pumps manufactured by Wilden Pump and Engineering Company are manufactured to the highest standards of quality and workmanship. Every pump is hydrostatically and functionally lested and guaranteed to operate as designed and meet our published performance curves. Materials and workmanship are guaranteed for one year from start-up or two years from shipment, whichever occurs first. Flow rates were deterimined by measurement into calibrated tanks and air consumption data was determined by the use of calibrated mass flow meters.

\section{Wilden offers more...}

More Sizes - Five sizes with flows from 0 to 230 GPM

More Elastomer Materials - Compatibility with any chemical solution.

\begin{abstract}
More Value - Lower prices and operating cosis
\end{abstract}

More Performance - Higher flows
More Pump Materials -. Aluminum, cast iron, 316 SS. Hastelloy C. polypropylene. PVDF, Teflon ${ }^{\star}$ PFA. 


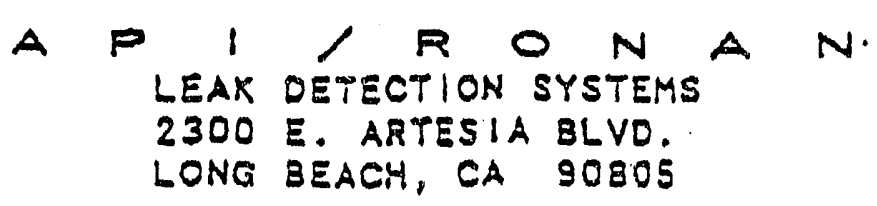

PHONE (213) $984-5380$

FAX (213) $984-5390$

To: Kelly Galloway

LOCATION:

COMPANY NAME: E Gt

FROM: Mettinamas

FAX NUMBER: $208-526-1928$

DATE: $4-23-22$

NUMBER OF PAGES INCLUDING THIS SHEEN:

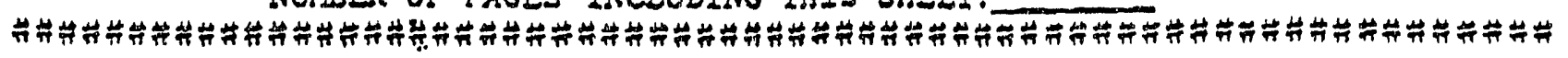

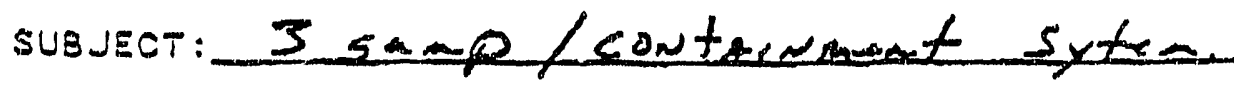

Kelly-

Then k won for your call and I mast Apolisize for not kolleng you back. Awobow

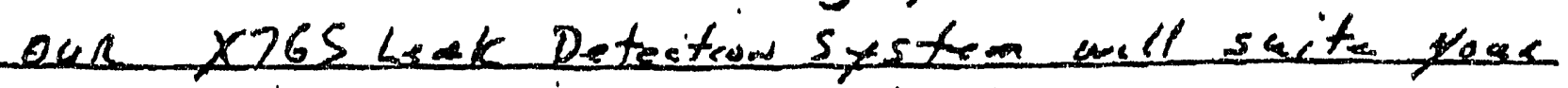
weeds. Please review attend soles into. The following modal \# will provide the there Liquid sensors, IS parries, LEP and Auxiliary Rel i on hon options.

$\times 26513-(3)<5-35+5 \operatorname{sacl}$ Listexiset 173500

Delivery 2-4 weeks

I w. ll call in tomonew $(4-24-92)$ and contain this fer.

thanks + Best as sands,

IF YOU OLD NOT RECEIVE THE NUMBER OF PAGES STATED LOVE, OR :F THE COPY IS NOT LEGIBLE, PLEASE CALL THE ABOVE NUMBER. 


\section{Series X76S Leak Detector System}

(1) $\overline{\text { RONAN }}$

Features

$\square$ Up to \& Input Modules with LED Indicators

$\square$ Audible and Visual Alarms

$\square$ Intrinsically Safe Interiace to Sensor

$\square$ Field-Proven Circuit Design

$\square$ NEMA Type I Enclosure

$\square$ Rugged Mechanical Design

다quid Level Sensors

- High Reliability

- Ul Listed

- Comparible wiri Hydrocarbons

- Maintenarce Free

$\square$ Alarm Conract Outpur per Sensor for Remote Indication or Telemetering

C Hydrostaric Leak Detector ior Double.wail Tanks

Q Positive Pressure Sensor for Pressurized Double-wall Tanks

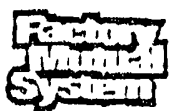

doproved

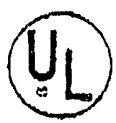

Listed $48 R 0$
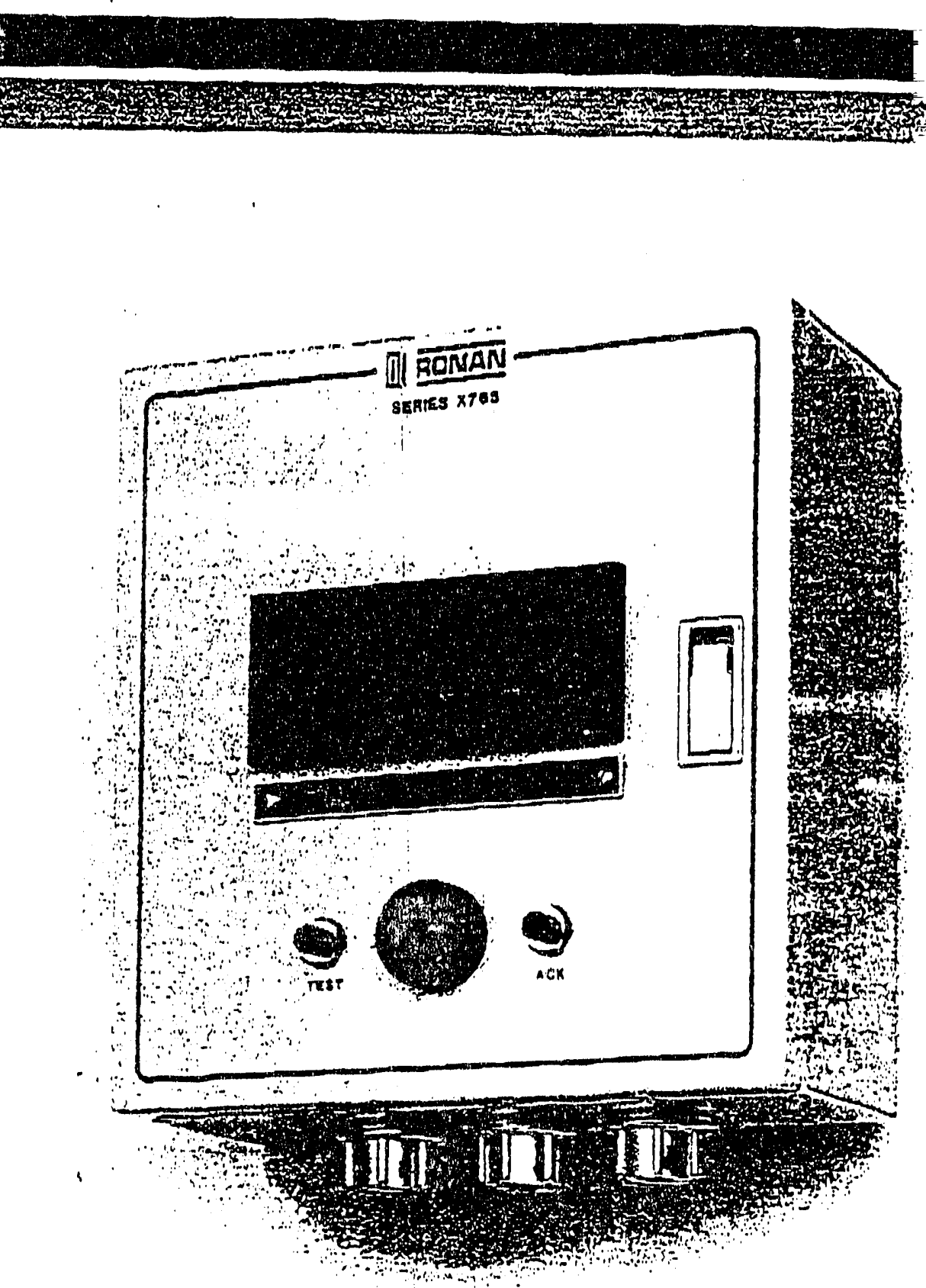

$\mathrm{T}$ he Model Xi6S Leak Detector System condinuousiy monitors underground storage tank installations for leakage of gasointe diesel oil, waste on and other hydrocarbons.

Two types of Liquid Level Sensors are horizontally or vertically positioned in the nomally dry arnular space of double-wailed tanks. Upon accumulation of product due to a leak the sensor will provide an audible and visual alarm.

Hydrostatic and air pressure sensors can provide monitoring of both the outer or inner shell of a doubiewall tank.

The sensor's outputs are continuousty supervised by individual alarm modules via FM approved intrinsically safe barriers. This allows installation of the sensors in Class 1. Division 1. Groups C. or D areas as defined in the National Elecirical Code without using costly conduits. conduit seals and explosion preof junction boxes.

The X76s provides up to four sensor alams. 


\section{W \\ Series X76S Leak Detector System}

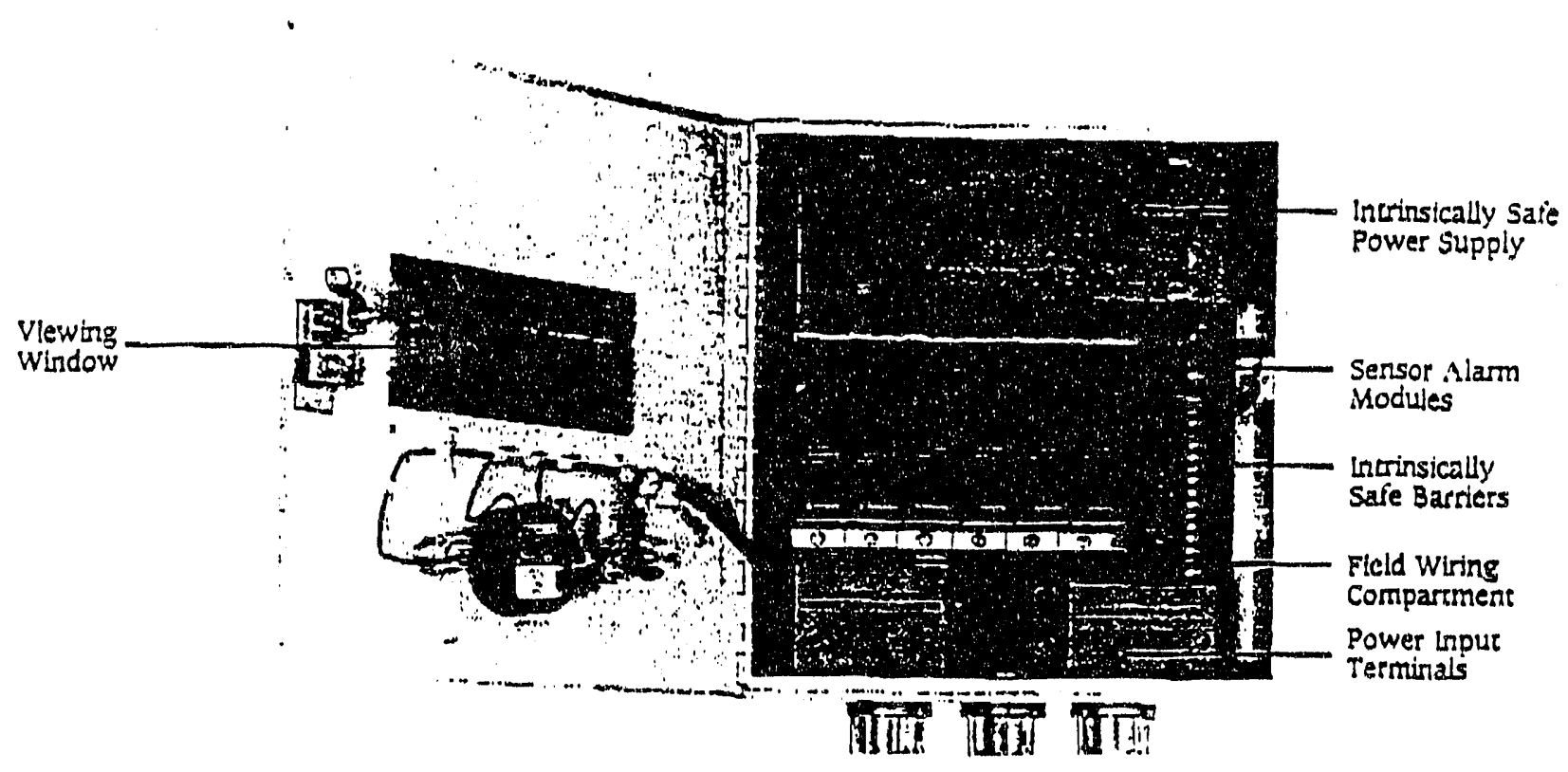

\section{The Sensors}

Model LS-3 N.C. \& HVA Tank Level Sensors

The Model LS-3 N.C. is most suitable for steel, double-wall tanks. The unit is posidioned vertically on the botrom of the cank annulus or at maximum ruel level of a rank io prevent overflow. The all-polysulfone leve! switch rearures a single-pole singlethrow contact, acruated by the tloat of rine unic. The concact stanis is annun. ciuted on the X76S monitor.

The HVA is a minianure liquid sensor for use in restricted vertical riser applications.

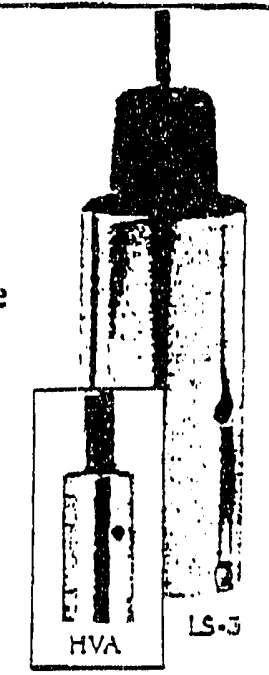

(U) Usied A8RO

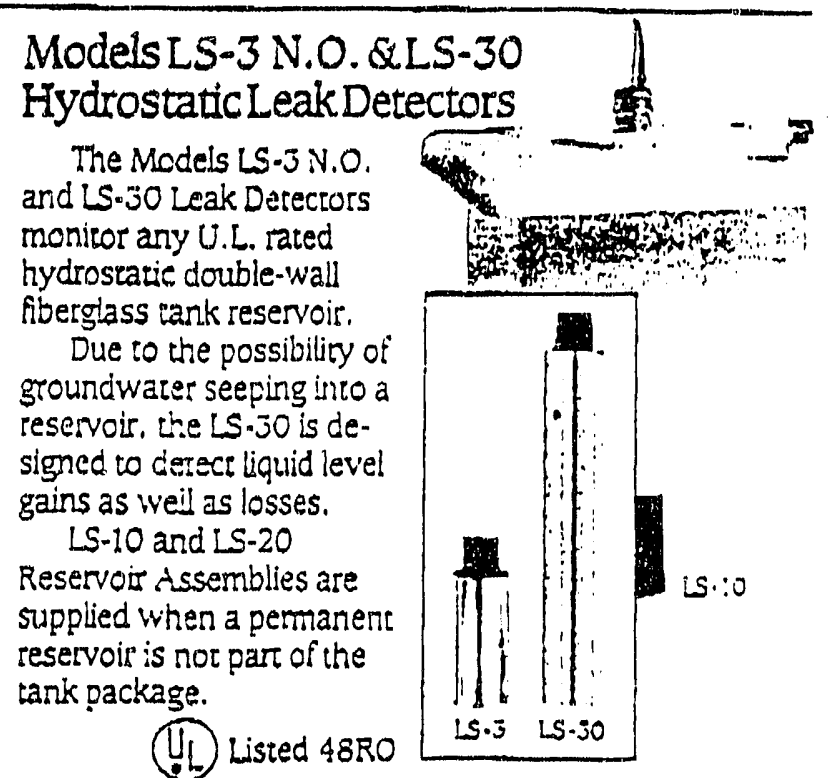

Models LS-3 N.O. \& LS-30
Hydrostatic Leak. Detectors

The Models LS.3.V.O. and LS-30 Leak Detectors monitor any U.L. rated hydrostarie double-wall fibergiass iank reservoir. Due to the possibility of groundwater seeping into a teservolr, the LS.3O is designed to cereci liquid leve gains as weil as losses. LS-10 and LS-20 Reservor Assemblies are supplied when a pemanent reservoir is nor part of the tank package.

(1) Listed 48RO

\section{Model JT-2 Tank Leak Sensor}

The ihodel TT-2 assembly consists of a pressure switch. fill valve and satery release vaive. The Model TT-ZP Positive Pressure Ieak Sersor is designed to provide monitoring of the anrular cavity of couble-wall tarks via air pressure. Any breach of the contairment will cause a pressure loss and will be sensed by the pressure switch transfiguring its contact should pressure fall below .5 PSIG.

The Model TT-2V Vacuum Leak Sensor monirors for loss of vacuum and will be sensed by the vacuum switch trans(1). Listed $48 R 0$ ferring its contacr should vacuun fall to .5 inches cisiseiciny. 


\section{Typical Installation}
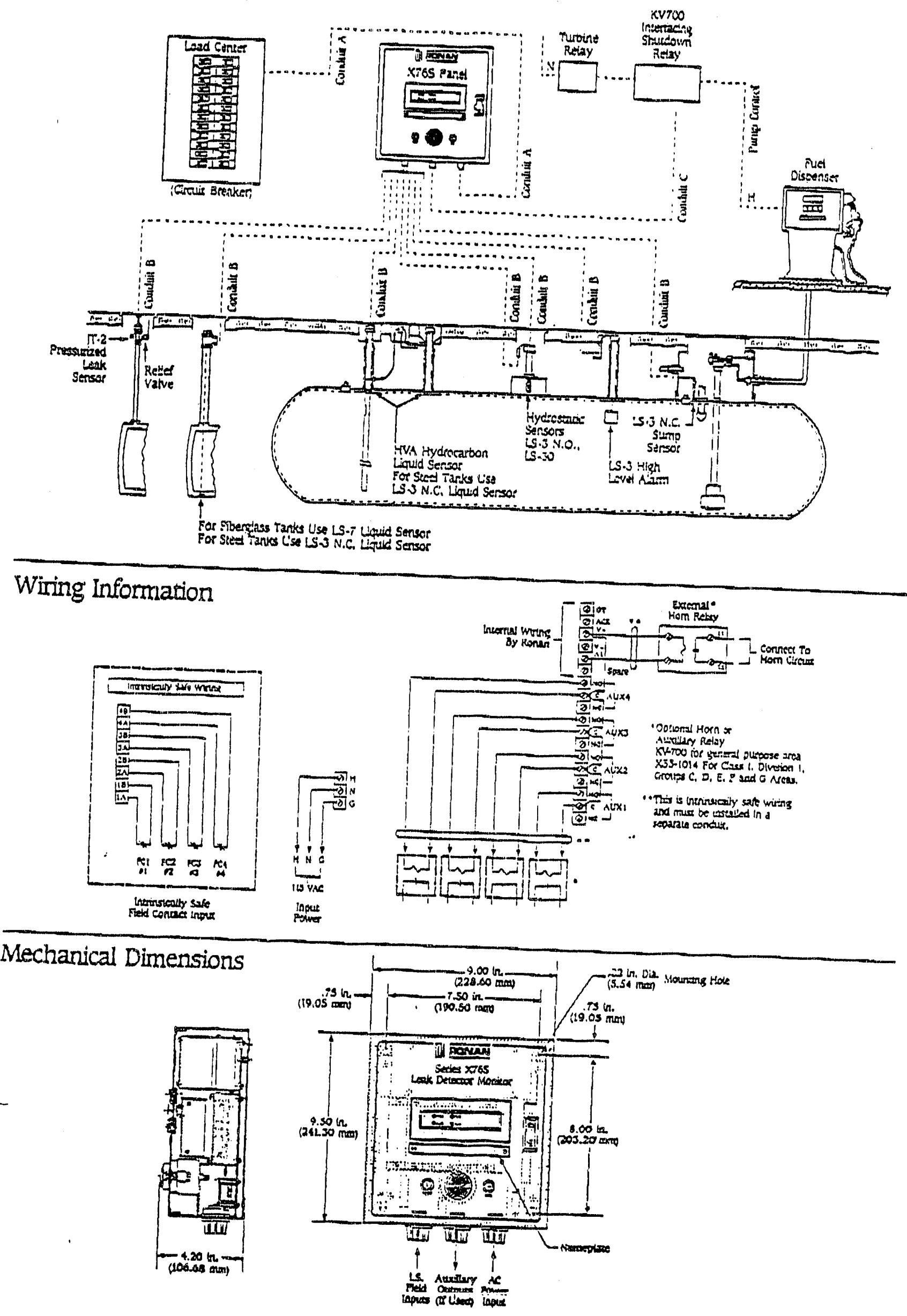
.r Spjecifications

System, Model X76S

Power: $115 \mathrm{Vac}, 60 \mathrm{~Hz}$

Power Consumpedon: $100 \mathrm{VA}$

Operading Temperature: $32^{\circ}$ to $165^{\circ} \mathrm{F}\left(0^{\circ}\right.$ to $\left.75^{\circ} \mathrm{C}\right)$

Dimensions: $9 \times 9.5 \times 4.2 \mathrm{in}$. $(22.86 \times 24.13 \times 10.67 \mathrm{~cm})$

Mounting: General purpuse area; wall mount

3 Approved. (IL) Lisied $48 R O$

Alarm Module

Field Sensor: Dry contact

Field Sensor Voltage: 115 Vac (supplied by XTES)

Number of Inputs: One per module

« Approved. (IL) Listed 4880

Intrinsically Safe Barrier Module X53

Number of Inputs: Two per module

Sensors Voltage: $24 \mathrm{Vdc}$. current limired

Sensors: Dry contact

Outpur Interface to Alarm Module: Relay contacr:

normally open/normally closed; selectable

Power Constumprion: $750 \mathrm{~mW}$ per inpur

Supply Voltage: $24 \mathrm{Vdc}$ from I.S. power supply

$\infty$ Approved. (I) Listed $48 \mathrm{R} 0^{\circ}$

Power Supply I.S. (Intrinsically Safe)

Power Inpur: $115 \mathrm{Vac}$

Outpur Voltage: $24 \mathrm{VdC}$

(im) Approved. (I) Listed 48Ro

Tank Leak Sensor, Model LS-3 N.C.

Housing: 304 stainless steel

Switch:

Type: SPST.V.C.

Raiving: $10 \mathrm{VA}$

Floar material: Buna-N

Pressure: 50 PSIG maximum

Leads: 20 AWG

(d) Listed 48.0

Tank Leak Sensor, Model IS-T

For steel and fiberglass double-wall tanks.

Housing Material: PVC (Geon 37241)

Liquid SpG: .70 minimum

Switch:

Type: SPST N.C.

Raring: $10 \mathrm{VA}$

Leads: 20 AWG

(di) Listed $48 \mathrm{RO}$

Hydrostatic Tank Leak Detectors,

Models LS-10 or LS-20

Reservoir:

Volume:

1.5-10. two gallons (7.47 liters)

IS-20, four gallons (15.16 liters)

Material: Poiyethylene plastic

Switches: Model LS-3 N.O. and LS-30

Dype: IS-3 N.O.. SPST: LS-30. DPDT

Raring: $10 \mathrm{VA}$

Floac macerial: Buna-N
Pressure: 50 PSIG maximum

Leads: 20 AWG

(11) Listed 48RO

HVA Mini Liquid Vertical Riser Sensor

Housing: Stainless steel

Contacts: Gold plated

Float: Gold plared alumirnum

Type: Single pole, normally open

Leads: 20 AWG

(1) Listed $\$ 8 \mathrm{RO}$

Tank Leak Sensor, Model JI-2

Housing: Stainless steel. explosion proof, hernedcally sealed, NEMA Types 7 and 9

Classification:

Class 1: Groups A, B, C and D

Cless 2: Groups $\mathrm{E}$. $\mathrm{F}$ and $\mathrm{G}$

Switch:

Type: SPDT N.O. (shalf condition)

Raring: $10 \mathrm{VA}$

Electrical Connection: $1 / 2$ in.-14 NPT with PVC-insulated
18 AWG leads

Pressure:

Setpoint: $\Pi-2$ Positive Pressure Leak Sensor, 5 PSIG,

TT-2V Vacuum Leak Sensor, .5 inches of mercury

Connection: $1 / 4 \mathrm{in} .-18 \mathrm{NFT}$

Adjustment: y in. Allen iwrench through port

Te mperatrre Range: $-40^{\circ}$ to $180^{\circ} \mathrm{F}\left(-40^{\circ}\right.$ 10 $\left.82^{\circ} \mathrm{C}\right)$

(4) Listed 48RO; CSA Approved 34146

\section{Ordering Information}

The Ronan Model X75S Leak Detecior Monitor System can be configured to mest the differene local and state codes for underground storage by proper selection of sensors and moniror modules. For example, a particular local code and/or type of facility may require leak detection of a iank annulus. The monitor sysiem would consist of the following items:

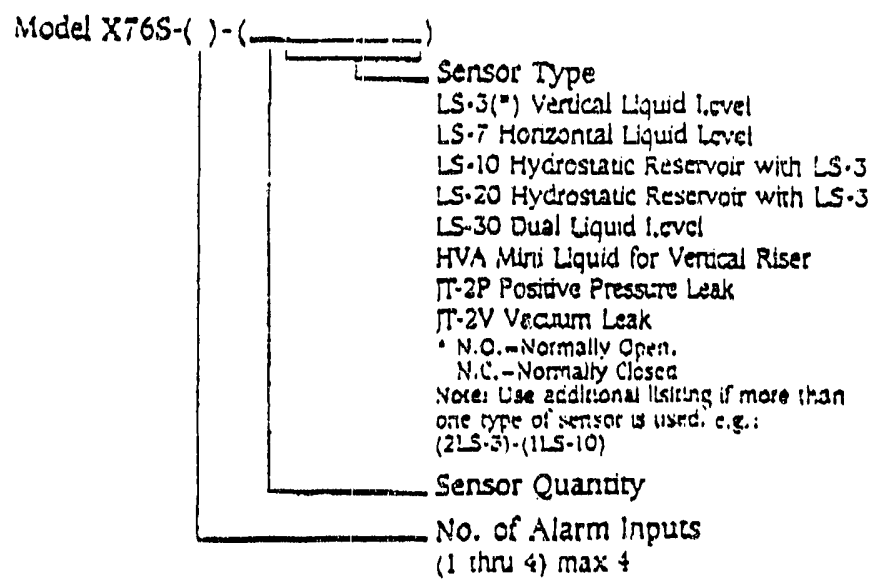

Warranty: Ronan war:anis equipment of its own manufacture to bs free frem defects in waterial and workmarship under nomal condlesons of use and service, and wilt repair or replace any componen: found io is detective on its reares. unspectarion charges frepaid, within one year of ics original purehase. This waranty' comries no liability, ejtior expressed or implied. beyond our objigacion to ieplace the unit which carries the warrany.
RONAN ENGTNEERENO COMPANY

P. O. BOX 1275

21200 Oxrand suet

Woodland Hilts.

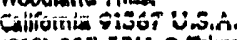

(818) 883.5211 - Telex 698.490

FNX (318) 992.0435
ronAN ENGONEERENG

UTD. U.R.

1 Timey Roed

Crownther olsoner 3

Westimgtan. Tyne and Wear

Washington. Tyne and Wear

(091) $416-1649 \cdot$ Telex 537.746

FAX (0.21) 416.5856
RONAN ENGTNEERNG

UKITIED

32 Bermordsey road

Torance. Oncaric

Carras M4BIZI

(A1A) is 52.0310 - Tetex 6.3662

FAx $(4=16) \quad 752.8072$
RONAN ENGINEERTLC

(AUST.) PTY. LDD.

Unir 10. 8 Leiginton Place

Homsby, w.S.w. 2077

Austratia

(D2) 477.7344 - Telex 7346T

BAX (02) 4776151 
APPENDIX D.

Sentry Polymers, Inc. Secondary Containment/ Leak Detection Specifications. 


\title{
$\beta$ -
}

\author{
SPECIFICATION \\ FOR LINING CONCRETE PITS \\ FOR THE PURPOSE OF LEAK DETECTION
}

\subsection{Scope:}

The intent of this specification is to provide a false floor and wall to accommodate leak detection in a concrete pit.

The sematone reinforced linims on the floor to be approximately 1 $3 / 4 "$ above the Inished surface of the concrete floor. This is to be accomplished by lngtalling 1 1/2" thick flberglass grating over the floor with a sheet of 1/8" FRP "iberglass factory nolded to one side facing up. The FRF grating and sheet to be secured in place using concrete anchors with washers installed on $36^{\prime \prime}$ centers.

The false walls to be accomplished using 1/8" thick flberglass sheet fastened to the walls using concrete anchors with washers. The comerete anchors are to be 1 istalled on $24^{\prime \prime}$ centers.

All Iiberglass sheet to be coated with a 125 mil lanirate ol Sembtone 870 and chopped strand mat with a nexus 100-10 surfacing veil.

\subsection{Matertals}

2.1 Coating Matertal: Semstone 870 Vingl Estar manufactured by Sentry polpmers. Freeport, Texas. No substitutes will be accepted.

2.2 Frimer: semstone 8084 Primer manufactured by Sentry Polymers, Freeport, Texas. No substitutes will be accepted.

2.3 Reinforcement: Fiberglass chopped strand mat, multidirectional, .75 or 1.5 oz. per $\mathrm{sg}$. ft.

2.4 Surfacing Ve11: Nexus 100-10 polyegtar surfacing vell.

2.5 Floor Covering: Fiberglasa covered grating, 1 1/2" thick X 1 $1 / 2^{\prime \prime}$ gquare mesh with .125" fiberglass sheet molded to one ide.

2.6 Wall covering: 1/8" thick pultruded flberglasa gheet. 
2.7 Concrete anchors: $3 / 8$ " diameter Stalniess Steel with washers manufactured by Hilti Corp., (or equal).

2.7 Detection pipe: FRP, with pipe cap, diameter to be at owners discretion, to be installed at location designated by owner.

NOTE: Pipe cap (no threads) to fit snug with attachment to detector pipe to prevent loss. Detector pipe to be coated with Semstone 870 and reinforced with fiberglass mat prior to installation.

\subsection{Drawings}

3.1 Supplied bo owner:

3.1 .1

$$
\text { 4.0 Qualits Control }
$$

4.1 Owner/Design enpineer to decide who will be responsible for quality control. Please mark an " $\mathrm{X}$ " on the appropriate line to indicate cholce.

\section{Owners Representative}

General Contractors Represencative

Application Contractor

Third Party; Specify:

4.2 Visually inspect covered grating installation on floors and fiberglass aheet on walls for propor anchoring into concrete.

4.3 Interfacing panel edges are not to exceed $1 / 4$ " at any intertace including concrete walla.

4.4 Visually ingpect surface preparation of fiberglass sheet to ingure that all glaze is removed and that the propile is similar to rough sandpaper.

4.5 Visualiy inspect that all corners have received a $I^{\prime \prime}$ radius with Semstone 8084 putt, prior to proceeding with application of Semstone 870 laminate. 
4.6 Visuall. inspect completed lined pit. Reasons for rejection are as follows:

A. Pinholes in lining,

B. Uncured material.

C. Foretgn inchusions in cured lining.

D. Inadequate thickness.

E. Use of materials not authorized in this specipication.

F. Exposed reinforcement / unwet mat.

G. Wrinkles or hollow spots in lining.

H. Unauthorized variance from this specification

\subsection{False ploor and wall installatios}

NoTE: In order to reduce field installation time it is recommended to take accurate field dimensions and pre-pabricate all 11005 and wall panela in a ghop environment. This will reduce field installation time to a minimum.

5.1 The floor of the concrete pit shall be covered using 1 1/2" thick fiberglasg grating with a lig" thick, flat, fiberglass panel molded to one side. The paneled side should face up. Anchor panels in place using $3{ }^{\prime \prime}$ Hilti Anchors. Set anchors at 24 " centers.

Note: Locate detector pipe locations and premeut holes in covered grating prior to instailation.

0.2 Set $1 / 8^{\prime \prime}$ thick flberplass panels against tho walls to within 3" from the top of the pit and anchor with $3 / 8$ " H1lti Anchors. Set anchors on 24 " centers.

\subsection{Semstone 870 Relnforced liner Installation}

Q. Abrastre blagt fiborglass panelg to remove any surpace contamination. mold releases andior surface glaze to achieve a 1-1/2 - 2 mil anchor propile.

6.2 Remove all blasting dust and debris by sweping and/or vacuuming.

6.3 Apply Semstone 8084 primer to all corners, from the corner to $2^{\prime \prime}$ out from the corner. Allow to set dry to touch.

8.4 Apply Semgtone 8034 putty to all corners to form a 1 " radius. 
6.5 Apply a basecoat of Semstone 870 and immediately embed a layer 1.5 oz, per sq. ft. Fiberglass chopped strand mat into the basecoat. Apply a coat of semstone 870 over the nat and work the surface with a serrated roller to remove entrapped ais. Repeat this sequence until (four layers of .75 oz per sq. Pt. chopped strand mat) or (two layers of $1.50 z$. per sq. It. chopped straud matl are completely saturated with Semstone 870 and all entrapped air is removed. Apols one laver of Nexus 100-10 gurfacing veil, saturate and remove all entrapped air. Allow to cure.

If the panels have been pre-fabricated, only the seams and anchor bolt heads need to have a laminate applied in the field. The seams should be 8 " wide with the nexus overlapped a minimum of $1 "$. The bolt beads should be encapgulated with a 6 " diameter laminate.

NOTE: Refer to specitic material data sheets lor mixing and application of Semstone 8084 , and Sematone 870 .

\section{D FRP leak Detector Pipe Ingtallation}

7.1 The FRP detector pipe ig to exterd a minimum distanco from the top of the pit in order to facilitate accesa.

7.2 Sand or abrasive blast approximateli 8 " from the end of the plpe to receive tio-in the bottom pit. Sand or abrasive blast approximatel. $8^{\prime \prime}$ around the perimeter of hole in the liner for the detector pipe.

7.3 Install. FRP detector pipe at location designated by owner ERP detector pipe locarion should ellow adequate apace for proper re-establishment of Semstone 870 liner.

7.4 Concractor is responsible for proper support of detector pipe.

7.5 Once the detector pipe is fitted and supported properly, apply a 1" radius of Semstone 8084 putty around pipe/floor interlace. Allow to cure.

7.6 Apply Semstone 870 and fibrglass chopped atrand mat approximatel. 6" out on to the horizontal and 6" up the vertical aurface to a finished thicknes of $250 \mathrm{mils}$ using a serrated rolier to remove entrapped air. Reper to Para. 6.5 


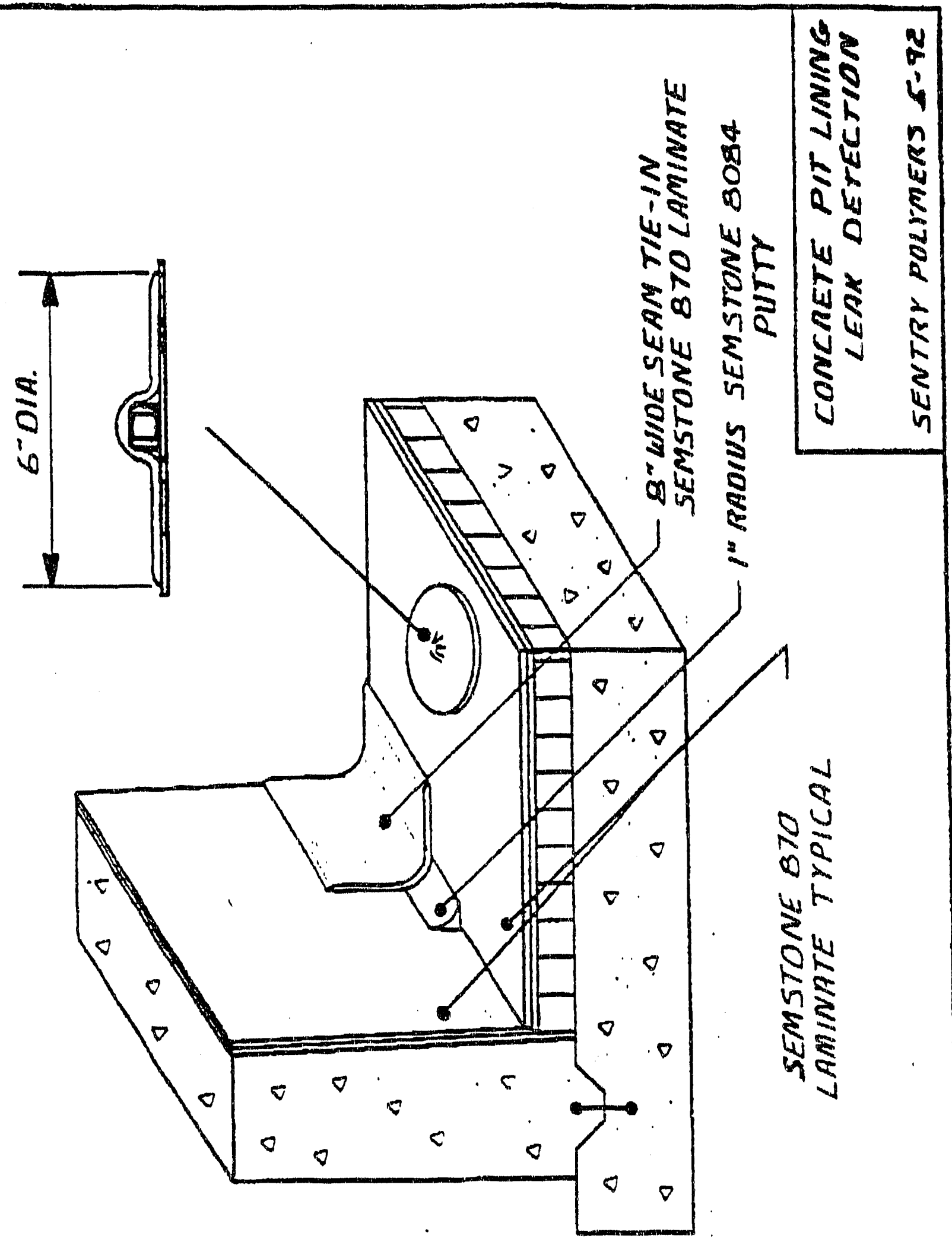


APPENDIX E.

Calculations for Material Costs. 


\section{Sump VES-FT-548: Secondary containment Liner System}

I. General Information

A. Liner Dimensions: $5.5 \mathrm{ft} \times 5.5 \mathrm{ft} \times 5.833 \mathrm{ft}$

(length $\times$ width $\times$ depth)

B. Surface Area Covered: 4 sides $(5.5 \mathrm{ft} \times 5.833 \mathrm{ft})=128.3 \mathrm{ft}^{2}$

1 floor $(5.5 \mathrm{ft} \times 5.5 \mathrm{ft})=+\frac{30.3 \mathrm{ft}^{2}}{158.6 \mathrm{ft}^{2}}$

C. Liner Material and Paint Sealant Costs:

Walls (870 laminate, panels, fiberglass, primer) $=\$ 8.53 / \mathrm{ft}^{2}$

Floor (grating, panels, 870 laminate) $=\$ 20.80 / \mathrm{ft}^{2}$ Leak Detection Pipe (1 ft diameter) $=\$ 70 / 1$ inear $\mathrm{ft}$

Paint Sealant for Sump Concrete (870 coating and primer) $=\$ 0.96 / \mathrm{ft}^{2}$

II. Sump VES-FT-548 Liner Cost Calculations

A. Wa11 Lining: $\left(128 \mathrm{ft}^{2}\right)\left(\$ 8.53 / \mathrm{ft}^{2}\right)=\$ 1,092$

B. Floor Lining: $\left(30 \mathrm{ft}^{2}\right)\left(\$ 20.80 / \mathrm{ft}^{2}\right)=\$ 624$

C. Leak Detection Pipe plus Lining

Pipe surface area $2 \pi r h=2 \pi(.5 \mathrm{ft})(7.5 \mathrm{ft})=23.6 \mathrm{ft}^{2}$

$(7.5 \mathrm{ft})(\$ 70 / \mathrm{ft})=\$ 525$ pipe

$\left(23.6 \mathrm{ft}^{2}\right)\left(\$ 8.53 / \mathrm{ft}^{2}\right)=\$ 201$ pipe laminate

$\$ 525$ pipe $+\$ 201$ lining $=\$ 726$

D. Total Liner System Material Cost Estimation

$\$ 1,092$ walls $+\$ 624$ floor $+\$ 726$ pipe and lining $=\$ 2,440$

III. Paint Sealant for Sump Concrete (paint coating plus primer) $\left(160 \mathrm{ft}^{2}\right)\left(\$ 0.96 / \mathrm{ft}^{2}\right)=\$ 153.60 \approx \$ 160$ 


\section{Sump VES-FT-549: Secondary containment Liner System}

I. General Information

A. Liner Dimensions: $6 \mathrm{ft} \times 6 \mathrm{ft} \times 11 \mathrm{ft}$

(length $x$ width $x$ depth)

B. Surface Area Covered: $4 \operatorname{sides}(6 \mathrm{ft} \times 11 \mathrm{ft})=264 \mathrm{ft}^{2}$

1 floor $(6 \mathrm{ft} \times 6 \mathrm{ft})=+\frac{36}{300} \mathrm{ft}^{2}$

C. Liner Material and Paint Sealant Costs:

Walls (870 laminate, panels, fiberglass, primer) $=\$ 8.53 / \mathrm{ft}^{2}$

Floor (grating, panels, 870 laminate) $=\$ 20.80 / \mathrm{ft}^{2}$ Leak Detection Pipe (1 ft diameter) $=\$ 70 / 1$ inear $\mathrm{ft}$

Paint Sealant for Sump Concrete (870 coating and primer) $=\$ 0.96 / \mathrm{ft}^{2}$

II. Sump VES-FT-549 Liner Cost Calculations

A. Wall Lining: $\left(2.64 \mathrm{ft}^{2}\right)\left(\$ 8.53 / \mathrm{ft}^{2}\right)=\$ 2,252$

B. Floor Lining: $\left(36 \mathrm{ft}^{2}\right)\left(\$ 20.80 / \mathrm{ft}^{2}\right)=\$ 749$

C. Leak Detection Pipe plus Lining

Pipe surface area $2 \pi r h=2 \pi(.5 \mathrm{ft})(12.5 \mathrm{ft})=39.3 \mathrm{ft}^{2}$

$(12.5 \mathrm{ft})(\$ 70 / \mathrm{ft})=\$ 875$ pipe

$\left(39.3 \mathrm{ft}^{2}\right)\left(\$ 8.53 / \mathrm{ft}^{2}\right)=\$ 335$ pipe laminate

$\$ 875$ pipe $+\$ 335$ lining $=\$ 1,210$

D. Total Liner System Material Cost Estimation

$\$ 2,252$ walls $+\$ 749$ floor $+\$ 1,210$ pipe and lining $=\$ 4,211$

III. Paint Sealant for Sump Concrete (paint coating plus primer) $\left(300 \mathrm{ft}^{2}\right)\left(\$ 0.96 / \mathrm{ft}^{2}\right)=\$ 288$ 


\section{Sump VES-FT-534: Secondary containment Liner System}

I. General Information

A. Liner Dimensions: $8.5 \mathrm{ft} \times 4 \mathrm{ft} \times 6 \mathrm{ft}$

(1 ength $x$ width $x$ depth)

B. Surface Area Covered: $2 \operatorname{sides}(4 \mathrm{ft} \times 6 \mathrm{ft})=48 \mathrm{ft}^{2}$

$2 \operatorname{sides}(8.5 \mathrm{ft} \times 6 \mathrm{ft})=102 \mathrm{ft}^{2}$

1 floor $(4 \mathrm{ft} \times 8.5 \mathrm{ft})=+\frac{34}{184} \mathrm{ft}^{2}$

C. Liner Material and Paint Sealant Costs:

Walls (870 laminate, panels, fiberglass, primer) $=\$ 8.53 / \mathrm{ft}^{2}$

Floor (grating, pane1s, 870 laminate) $=\$ 20.80 / \mathrm{ft}^{2}$

Leak Detection Pipe (1 ft diameter) $=\$ 70 / 1$ inear $\mathrm{ft}$

Paint Sealant for Sump Concrete (870 coating and primer) $=\$ 0.96 / \mathrm{ft}^{2}$

II. Sump VES-FT-534 Liner Cost Calculations

A. Wall Lining: $\left(150 \mathrm{ft}^{2}\right)\left(\$ 8.53 / \mathrm{ft}^{2}\right)=\$ 1,280$

B. Floor Lining: $\left(34 \mathrm{ft}^{2}\right)\left(\$ 20.80 / \mathrm{ft}^{2}\right)=\$ 707$

C. Leak Detection Pipe plus Lining

Pipe surface area $2 \pi r h=2 \pi(.5 \mathrm{ft})(7 \mathrm{ft})=22 \mathrm{ft}^{2}$

$(7 \mathrm{ft})(\$ 70 / \mathrm{ft})=\$ 490$ pipe

$\left(22 \mathrm{ft}^{2}\right)\left(\$ 8.53 / \mathrm{ft}^{2}\right)=\$ 188$ pipe laminate

$\$ 490$ pipe $+\$ 188$ lining $=\$ 678$

D. Total Liner System Material Cost Estimation

$\$ 1,280$ walls $+\$ 707$ floor $+\$ 678$ pipe and lining $=\$ 2,665$

III. Paint Sealant for Sump Concrete (paint coating plus primer)

$\left(184 \mathrm{ft}^{2}\right)\left(\$ 0.96 / \mathrm{ft}^{2}\right)=\$ 177 \approx \$ 180$ 

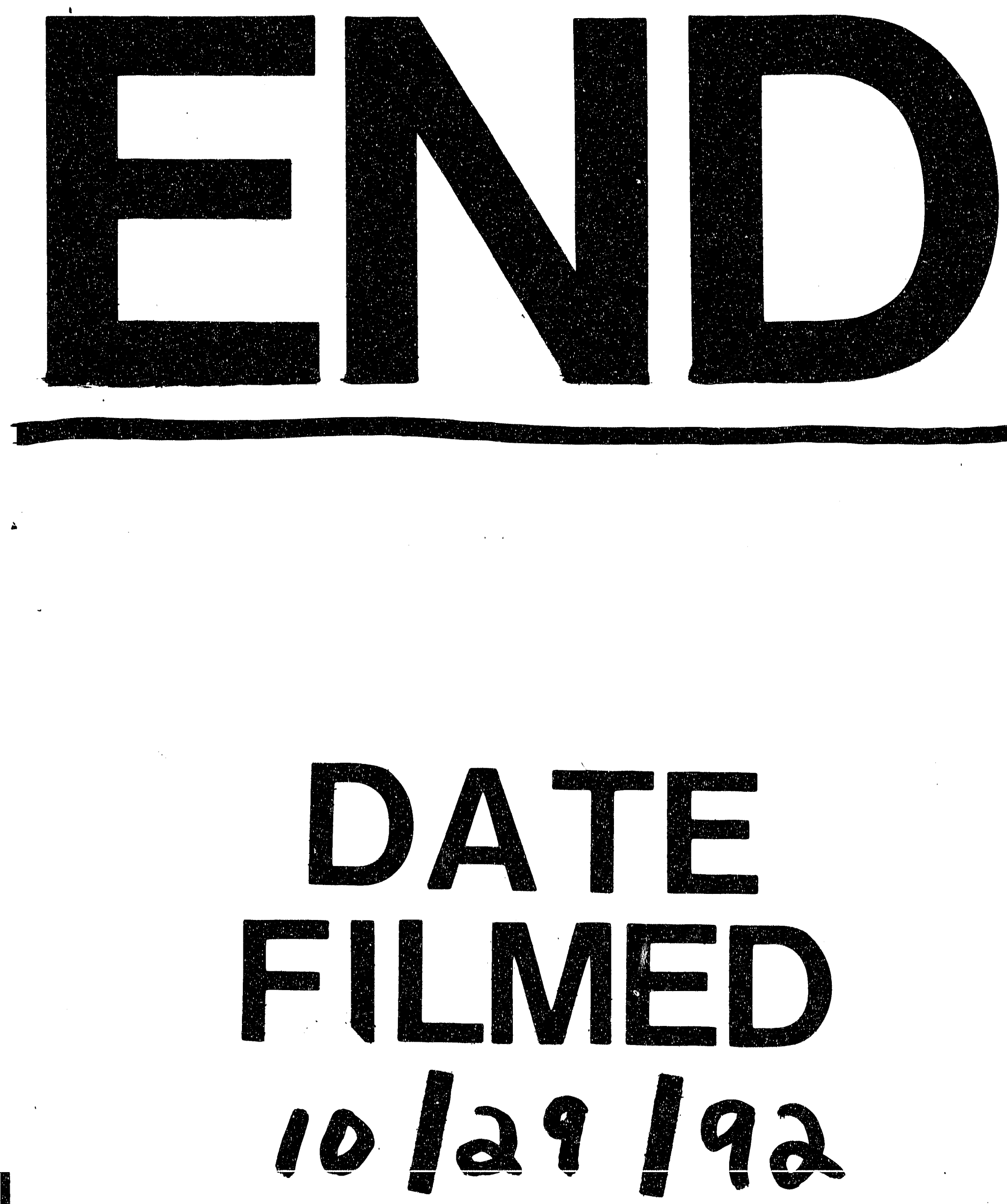
